NBER WORKING PAPER SERIES

\title{
THE CHILDREN OF HOPE VI DEMOLITIONS: NATIONAL EVIDENCE ON LABOR MARKET OUTCOMES
}

\author{
John C. Haltiwanger \\ Mark J. Kutzbach \\ Giordano E. Palloni \\ Henry Pollakowski \\ Matthew Staiger \\ Daniel Weinberg
}

Working Paper 28157

http://www.nber.org/papers/w28157

\author{
NATIONAL BUREAU OF ECONOMIC RESEARCH \\ 1050 Massachusetts Avenue \\ Cambridge, MA 02138 \\ November 2020
}

Any opinions expressed herein are those of the authors and do not represent the views of the U.S. Census Bureau or the Federal Deposit Insurance Corporation. All results have been reviewed to ensure that no confidential information is disclosed (q.v. U.S. Census Bureau Disclosure Review Board numbers: DRB-B0038-CED-20190405, DRB-B0071-CED-20190829, and CBDRB-FY20CED0060029). Much of the work for this analysis was done while Mark Kutzbach was an employee of the Census Bureau. John Haltiwanger was a Schedule A (part-time) employee and Matthew Staiger a Pathways Intern of the U.S. Census Bureau at the time of the writing of this paper. This research has been supported by grant number 98082 from the "How Housing Matters" research program of the John D. and Catherine T. MacArthur Foundation, by NSF grant number 1730108, by a Research Partnership grant from the U.S. Department of Housing and Urban Development, and by a grant from the Russell Sage Foundation. This research uses data from the Census Bureau's Longitudinal Employer Household Dynamics Program, which was partially supported by the following National Science Foundation Grants: SES-9978093, SES-0339191, and ITR-0427889; a National Institute on Aging Grant AG018854; and grants from the Alfred P. Sloan Foundation. The authors want to thank Mark Heller for valuable research assistance and Lydia Taghavi of HUD for data assistance. We thank James Spletzer, Erika McEntarfer, Katherine O'Regan and Amy Ellen Schwarz as well as participants at the Urban Economics Association, American Real Estate and Urban Economics Association, Association for Public Policy and Management, and Southern Economics Association meetings for comments. The views expressed herein are those of the authors and do not necessarily reflect the views of the National Bureau of Economic Research.

NBER working papers are circulated for discussion and comment purposes. They have not been peer-reviewed or been subject to the review by the NBER Board of Directors that accompanies official NBER publications.

(C) 2020 by John C. Haltiwanger, Mark J. Kutzbach, Giordano E. Palloni, Henry Pollakowski, Matthew Staiger, and Daniel Weinberg. All rights reserved. Short sections of text, not to exceed two paragraphs, may be quoted without explicit permission provided that full credit, including () notice, is given to the source. 
The Children of HOPE VI Demolitions: National Evidence on Labor Market Outcomes

John C. Haltiwanger, Mark J. Kutzbach, Giordano E. Palloni, Henry Pollakowski, Matthew

Staiger, and Daniel Weinberg

NBER Working Paper No. 28157

November 2020

JEL No. I38,J13,J31,J62,R23

\begin{abstract}
We combine national administrative data on earnings and participation in subsidized housing to study how the demolition of 160 public housing projects - funded by the HOPE VI programaffected the adult labor market outcomes for 18,500 children. Our empirical strategy compares children exposed to the program to children drawn from thousands of non-demolished projects, adjusting for observable differences using a flexible estimator that combines features of matching and regression. We find that children who resided in HOPE VI projects earn 14\% more at age 26 relative to children in comparable non-HOPE VI projects. These earnings gains are strongest for demolitions in large cities, particularly in neighborhoods with higher pre-demolition poverty rates and lower pre-demolition job accessibility. There is no evidence that the labor market gains are driven by improvements in household or neighborhood environments that promote human capital development in children. Rather, subsequent improvements in job accessibility represent a likely pathway for the results.

John C. Haltiwanger

Department of Economics

University of Maryland

College Park, MD 20742

and NBER

haltiwan@econ.umd.edu

Mark J. Kutzbach

Center for Financial Research

Federal Deposit Insurance Corporation

550 17th Street NW, MB-2127

Washington, DC 20429

mkutzbach@fdic.gov

Giordano E. Palloni

International Food Policy Research Institute

1201 Eye St.. NW

Washington, DC 20005

g.palloni@cgiar.org

Henry Pollakowski

Graduate School of Design

Harvard University

Cambridge, MA 02138

hpollakowski@gsd.harvard.edu

Matthew Staiger

Department of Economics

University of Maryland

College Park, MD 20742

mstaiger@umd.edu

Daniel Weinberg

Principal, DHW Consulting

2501 Lisbon Ln.

Alexandria, VA 22306

dhweinberg@gmail.com
\end{abstract}




\section{Introduction}

The concern that placement in subsidized housing, especially large public housing projects in high-poverty neighborhoods, could negatively affect children has been the focus of a substantial literature. ${ }^{1}$ Based partly on this rationale, the last 30 years of federal assisted housing policy has sought to deconcentrate subsidized housing participants, mainly through the provision of Housing Choice Vouchers (hereafter, vouchers) that subsidize low-income families to live in marketsupplied housing. A significant effort to spur the dispersion of these households has focused on the demolition of public housing projects paired with support for existing residents to find alternative housing, most notably under the U.S. Department of Housing and Urban Development's (HUD's) HOPE VI program. ${ }^{2}$ Despite the growing availability of vouchers and the continued funding of programs intended to reduce the population living in low-quality public housing projects, there is little representative evidence about how these demolitions affect shortor long-term outcomes for exposed children and adults; much of the existing research on subsidized housing is conducted in a limited number of large metropolitan areas and it is not clear how these findings apply to other contexts in the U.S.

This paper explores how the HOPE VI Demolition program affected the adult labor market outcomes of children who resided in demolished projects. Using a unique dataset available at the U.S. Census Bureau — which links administrative data on earnings and participation in subsidized housing — we identify approximately 18,500 children exposed to 160 HOPE VI demolitions in diverse environments across the U.S. Our empirical strategy for estimating the causal impacts of the program is based on the observation that even though the HOPE VI program systematically targeted the "worst" public housing projects, there were many similarly distressed projects in equally disadvantaged neighborhoods that were not demolished. We leverage the richness and size of the data by using a stratification with regression estimator (Imbens and Rubin 2015), which combines features of both matching and regression in order to flexibly account for observable differences between the 160 HOPE VI projects and 8,800 public housing projects unaffected by the program.

\footnotetext{
${ }^{1}$ For example, Oreopoulos (2003), Jacob (2004), Chetty et al. (2016), Andersson et al. (2018a), and Chyn (2018).

${ }^{2}$ The HOPE VI program, originally known as the Urban Revitalization Demonstration, was the sixth of the Housing Opportunities for People Everywhere Grants, funded by P.L. 102-389 (HUD 2007).
} 
Our main finding is that exposure to the HOPE VI Demolition program between the ages of 10 and 18 produced substantial long-run labor market benefits, increasing age 26 earnings by 14.2\% relative to comparable children from non-HOPE VI projects. Interestingly, we find that the positive impacts are driven by children from projects in neighborhoods served by the larger housing authorities typically located in large metro areas. For example, we estimate that HOPE VI increased earnings by $19.5 \%$ in large (greater than 2,500 units) Public Housing Authorities (PHAs), compared to a statistically insignificant $4.5 \%$ increase in smaller PHAs.

We start our investigation of mechanisms by studying the short- and medium-term impacts of the program. The demolitions led to large changes in housing circumstances, forcing most HOPE VI households out of their initial projects and into other public housing projects or the voucher program. While households exited subsidized housing at a higher rate in the year after the demolition, there is no evidence that the program displaced households from subsidized housing entirely in later years. ${ }^{3}$ Despite the changes in project and subsidy type, the HOPE VI-induced moves did not produce measurable changes in school quality, neighborhood economic and demographic characteristics, or the labor market outcomes of parents. Furthermore, we find no evidence of larger impacts for children who were younger at the time of a demolition. Together, these results suggest that the long-term labor market benefits of HOPE VI demolitions are not driven by increased exposure to better neighborhoods during childhood, at least as such neighborhood effects are characterized elsewhere in the literature (Chetty et al. 2016).

Rather, the strongest evidence suggests that HOPE VI improved long-run labor market outcomes by affecting the characteristics of the neighborhoods where the children moved to and ended up living as adults. Specifically, we find that HOPE VI led to a significant improvement in measures of the geographic proximity of job opportunities - jobs per person, average commute time, and a job proximity index constructed by HUD — in the neighborhoods that the children were living in 2010, 7-13 years after the demolitions. ${ }^{4}$ Improved job proximity can reduce job search and commuting costs and therefore reduce job search duration (Andersson et al. 2018b) and encourage individuals on the margin between working and not working to increase search effort

\footnotetext{
${ }^{3}$ While it is quite common for residents of HOPE VI projects to exit subsidize housing, they are no more likely to do so relative to residents of other similarly distressed projects that were not exposed to the HOPE VI program.

${ }^{4}$ Our results point to a spatial concept of job accessibility which we refer to as job proximity. While it is also possible that the program could have moved children into neighborhoods that provided better access to jobs through labor market networks, we find no evidence that this is the case.
} 
and participate in the labor market (Smith and Zenou 2003). Consistent with job accessibility being an important mechanism, we find that an important part of the observed earnings gains are driven by an extensive margin labor supply response.

The data suggest that improvements in job accessibility occurred through two distinct channels. First, the demolitions transformed the neighborhoods in which the HOPE VI projects were originally located. Public housing projects, particularly those served by large PHAs, often provide housing to many individuals in geographically concentrated areas. This results in neighborhoods that provide limited access to jobs, with many job searchers competing for nearby jobs. The demolition of public housing projects drastically reduced population density with no corresponding decrease in the number of jobs in the neighborhood. Thus, on average, children that remained near the location of their original project, experienced an improvement in job proximity.

Second, HOPE VI increased the likelihood that households moved, and destination neighborhoods provided better access to jobs, even though these neighborhoods were typically geographically close (within the same county) and similarly poor. This pattern of moves is explained by two features in the data: 1) HOPE VI projects in large PHAs were located in neighborhoods that were especially disadvantaged in terms of both poverty rates and job accessibility relative to surrounding areas; and 2) housing prices increase sharply with reductions in neighborhood poverty but there is no similar price gradient with respect to job accessibility. Together, this suggests that while local moves induced by HOPE VI were likely to generate improvements in job accessibility, financial constraints may have prevented reductions in neighborhood poverty. The latter observation is consistent with existing research on the Voucher program (Patterson et al. 2004; Eriksen and Ross 2013; Jacob, Ludwig, and Miller 2013; Collinson and Ganong 2018; Andersson et al. 2018a).

In relation to previous work, an important contribution of this paper is to obtain estimates of the long-term impact of a large assisted housing program that are more representative of the full population of affected projects. Much of the relevant prior empirical research relies on data from a limited set of large metropolitan areas. Figure A.1 plots the distribution of the size of PHAs that participated in three important randomized controls trials including the HUD Moving to Opportunity (MTO) experiment (Ludwig et al. 2013), the Gautreaux program (Rosenbaum 1995), and the Effects of Housing Choice Voucher on Welfare Families project (Mills et al. 2006). ${ }^{5}$

\footnotetext{
${ }^{5}$ Similarly, non-experimental research on the consequences of changes in access to vouchers or increases in voucher
} 
Approximately half of all public housing units are located in small PHAs but only two of the ten PHAs in this previous research are located in small PHAs. In contrast, over two thirds of the PHAs that received HOPE VI funding are located in small PHAs. Thus, our results are likely to be more representative of the effects for the broader population in public housing. Chicago is the third largest PHA and is shown separately in Figure A.1 as it is the setting for Chyn (2018), the closest existing paper to our work. Chyn (2018) studies the long-term earnings impacts of public housing project demolitions in Chicago and also finds substantial long-term benefits; estimating that demolitions increased earnings for children in affected buildings by $16 \%$ relative to unaffected children who resided in the same projects. ${ }^{6}$ Our results provide additional evidence on the longterm benefits of the demolitions of distressed public housing projects in contexts beyond Chicago and provide more insight into the mechanisms through which these demolitions affected long-term labor market outcomes.

Our results also shed light on an open puzzle in the existing literature: Does inducing households to move to new neighborhoods have to occur while children are still young in order to have long-run benefits? Chyn (2018) and the results in our paper suggest that demolitions do produce long-run benefits for older children (older than 13 at the time of the demolition). Conversely, in their analysis of the MTO experiment, Chetty et al. (2016) find no evidence of longrun gains for older children who transitioned from public to voucher housing. ${ }^{7}$ One explanation for this discrepancy suggested by Chyn (2018) is that the projects in his study were in much more disadvantaged neighborhoods relative to those in MTO. If older children only benefit when the origin neighborhood is especially distressed, this could reconcile the findings from MTO, Chyn (2018), and this paper. We exploit the variation in pre-demolition neighborhood characteristics

generosity, identifies treatment effects for a small set of non-representative cities, as in Collinson and Ganong (2016). An exception is a companion paper-Anderson et al. (2018a) - which uses a household fixed-effects identification strategy and finds long-term benefits of time spent in public and voucher housing between the ages of 13 and 18 . Anderson et al. (2018a) use data from nearly the universe of assisted housing participants so that the results capture the typical effect of participating in the public housing or voucher program. In contrast, the current paper focuses on a population that is more disadvantaged relative to the subsidized housing population as a whole.

${ }^{6}$ Chyn (2018) measures earnings between the ages of 19 and 32 whereas we focus on labor market outcomes measured at age 26. Some of the projects studied in Chyn (2018) and Jacob (2004), who studied the short-run impacts of the same demolitions, were demolished under the HOPE VI program.

${ }^{7}$ The MTO study randomly assigned 4,600 households living in public housing projects to a control group, a "Section 8 " group which was offered standard vouchers, or an experimental group which was offered vouchers that could only be used in census tracts with a 1990 poverty rate below 10\%. The primary comparison made by Chetty, et al. (2016) is between this experimental group and the control group. Their results thus rely on moves to lower poverty neighborhoods, a case in which it makes sense that younger children should benefit more. Survey and administrative data have provided means of evaluating the impact of the two treatments (Ludwig et al. 2013). 
and find that HOPE VI had the largest impact on age 26 earnings for projects located in neighborhoods that had higher poverty rates, were more densely populated and had lower measures of job proximity. Intuitively, large distressed public housing projects create an environment in which there are many more people looking for work relative to the jobs available nearby, and this creates barriers to employment. The children located in these neighborhoods - even if they were exposed to the program only later in adolescence — still benefited from the HOPE VI intervention.

The paper proceeds as follows. Section 2 provides background on the HOPE VI program and related research and discusses the potential mechanisms through which public housing demolitions could affect the long-term well-being of children in displaced households. Section 3 describes the data sources and sample construction. Section 4 highlights challenges for the identification of unbiased treatment effects and discusses the stratification with regression estimator. Section 5 presents the empirical results, and Section 6 concludes.

\section{Background and Anticipated Impacts of the Program}

HUD launched the HOPE VI initiative in response to the report by the National Commission on Severely Distressed Public Housing (NCSDPH), which, in 1992, found that 86,000 of the 1.4 million public housing units nationwide qualified as "severely distressed" (NCSDPH 1992, HUD 2007). HOPE VI consisted of two main programs designed to address this issue: (1) the Demolition program, which provided funding for the demolition of public housing projects and the relocation of affected residents, and (2) the Revitalization program, which provided funding to redevelop neighborhoods with public housing into low-density, mixed-income communities. The focus of our paper is strictly on the Demolition program and unless otherwise noted, any mention of HOPE VI refers solely to this program. ${ }^{8}$ Between 1996 and 2003, HUD awarded \$392 million through 285 HOPE VI grants for the demolition of more than 57,000 public housing units. Displaced households were typically either offered an apartment in another public housing project, a voucher, or they were forced out of subsidized housing altogether (Popkin et al. 2004). ${ }^{9}$ Research tracking the former residents of a limited set of demolished public housing

\footnotetext{
${ }^{8}$ There is some overlap between the Revitalization and Demolition programs so that some recipients of a Demolition grant later received a Revitalization grant. However, the Revitalization intervention typically began years after the demolition occurred. As we discuss in Appendix B, we find no evidence that our estimated impact of the Demolition program is affected by the Revitalization program.

${ }_{9}^{9}$ Displaced households could also be offered a unit in a revitalized HOPE VI site, but substantial lags were involved.
} 
projects estimates that about half of displaced households moved to a new public housing project, a third were provided with a voucher and the remainder exited subsidized housing altogether (Kingsley et al. 2003; Popkin et al. 2009).

HOPE VI Demolition grants were awarded based on a competitive process in which HUD posted a notice of funding availability, PHAs submitted applications and HUD selected a limited set of awardees (Murphy 2012). Any PHA was eligible to submit an application for the demolition of severely distressed public housing developments (using the NCSDPH criteria). However, at least in the earliest year, HUD explicitly differentiated between PHAs of various sizes in their call for funding (2,500 units or less, between 2,501 and 10,000 units, and over 10,000 units); applicants were evaluated within these groups and group size determined the amount of funding for which PHAs were eligible. Our analysis often differentiates between large (more than 2,500 units) and small (2,500 or fewer units) PHAs based on these cutoffs. ${ }^{10}$ Each year, HUD classified applicants into one of four priority groups, and grants were awarded (conditional on eligibility and approval) on a first-come, first-served basis by priority group until funds were exhausted. ${ }^{11}$ Given limited funding, both the number of applicants and eligible projects exceeded the number of awards. ${ }^{12}$ Furthermore, many eligible projects never applied for funding while some non-distressed projects received funding, leaving many distressed-projects unaffected by HOPE VI. Indeed, Turner et al. (2007) estimate that there were between 47,000 to 82,000 severely distressed units that remained in public housing inventory as of 2007 (four years after the last demolition grant award). We return to these points later in our discussion of the empirical strategy.

It is not obvious how we should expect HOPE VI to affect the long-term labor market outcomes of displaced children. A primary goal of the program was to move families out of environments characterized by a "high incidence of crime," physical deterioration "that renders

\footnotetext{
${ }^{10} \mathrm{We}$ do not further differentiate the large PHA sample because there are too few HOPE VI projects in PHAs that exceed 10,000 units in our sample to analyze separately.

${ }^{11}$ Different sources give slightly different accounts of the award process. However, the Congressional Research Service Report RL32236, describes the first-come, first-served process and notes that the "priority groups are, in order of priority, (1) approved for a 202 conversion, (2) applied for a 202 conversion, (3) approved for a Section 18 demolition, or (4) approved for a HOPE VI revitalization grant. Section 202 Mandatory Conversion is the conversion of public housing developments to Section 8. If it costs less to give the residents a Section 8 voucher, rather than maintain the low rent public housing building, the building is shut down and the residents are given Section 8 vouchers."

${ }^{12}$ On average only $53 \%$ of applicants were funded each year. The percentage is based on the authors' calculation using publicly available data (HUD 2007) and the statistic excludes data from 1996, for which we do not know the number of applicants.
} 
the housing dangerous to the health and safety of its residents" and "limited opportunities for meaningful employment of residents." ${ }^{13}$ Based on these stated objectives, demolitions could have shaped the development of children by improving the home and neighborhood environments they were exposed to while young. This would be consistent with recent empirical evidence suggesting that neighborhood conditions in childhood can affect the development of human capital, which in turn affect long-term labor market outcomes (Chetty et al. 2014, 2016; Chetty and Hendren 2018). Alternatively, the program could have affected adult labor market outcomes by changing access to jobs in the neighborhoods where children end up living as young adults. Theory highlighting the potential importance of job accessibility dates back to Kain (1968), arguing that the geographic location of jobs and job seekers can have important implications for labor market outcomes; recent empirical evidence in Andersson et al. (2018b) supports this hypothesis.

The program also could have had an adverse effect. Home and neighborhood environment could have worsened if the program forced people from their homes without providing proper relocation support. In addition, by dispersing residents that previously lived close to one another, the program could have disrupted social networks. Indeed, this was a major concern for residents like George Moses, a former long-time resident of public housing and the Chair of the Board of Directors of the National Low Income Housing Coalition, who spoke in objection to the HOPE VI program at a congressional hearing in 2007: "in my neighborhood, people would gather to talk, watch one another's children, and form strong bonds. When we tear these neighborhoods apart, $[\ldots]$ the impact is both immediate and long-lasting."

The existing empirical research on HOPE VI is largely descriptive but it suggests that the program had limited success in achieving its short-term goals. Popkin et al. $(2004 ; 2009)$ find that households affected by HOPE VI experienced large changes in housing and most households moved to neighborhoods with lower poverty rates and less crime, and reported being more satisfied with their new neighborhoods, particularly if they received vouchers. However, most research finds little evidence that HOPE VI affected the short-term labor market outcomes of adults (Goetz 2010; Jones and Paulsen 2011; Popkin et al. 2009) or the health, education or behavioral outcomes of the children (Gallagher and Bajaj 2007). A limitation of this research is that it primarily documents how outcomes changed over time for households exposed to the program. This is

\footnotetext{
${ }^{13}$ Quotes are from NCSDPH (1992).
} 
particularly problematic in the HOPE VI setting because, even in absence of demolitions, households in public housing exhibit a high degree of residential mobility (McClure 2018).

Jacob (2004) is an exception to this descriptive work, obtaining credible causal estimates of the demolition of public housing projects by comparing outcomes for children who resided in buildings that were demolished to children who resided in buildings that were not demolished but were located within the same project. Jacob (2004) finds no evidence of short-term gains in educational outcomes. In the only research on the long-term outcomes of demolitions for children, Chyn (2018) uses a similar empirical strategy and finds positive impacts on adult labor market outcomes. These results suggest that a lack of short-term impacts does not preclude the possibility of longer-term effects on labor market outcomes. However, the results from Jacob and Chyn may not be representative of the HOPE VI program as a whole since their sample is limited to public housing residents in Chicago. An important contribution of our paper is to obtain more representative estimates of the impact of the HOPE VI program by studying 160 demolitions that occurred in diverse environments across the U.S. In contrast to Jacob (2004) and Chyn (2018), we observe a great deal of variation in project and neighborhood characteristics within our empirical sample. This enables us to empirically assess how the impact of the HOPE VI program differed across projects located in heterogeneous pre-program contexts.

\section{Description of the Data}

The data requirements for this project are substantial. We need to be able to identify children and parents affected by public housing project demolitions, track exposed and nonexposed residents as they move across subsidized housing programs and neighborhoods, and match the children's housing and residential experiences to their labor market outcomes as adults. We overcome these challenges by combining two key data sources: (1) HUD-PIC (Public and Indian Housing Information Center) administrative records of participation in subsidized housing, and (2) the Census Bureau's Longitudinal Employer-Household Dynamics (LEHD) Infrastructure Files, an administrative records system for employer-employee matched data. Below, we describe these sources and discuss how we integrate them to construct our sample.

\subsection{Data Sources}

HUD-PIC tracks public housing and voucher recipients during our study period. As part of their housing occupancy verification process, PHAs provide HUD with the identities of residents, 
which HUD then compiles into an annual relational database. Absent the coverage limitations we discuss below, these files record every individual participating in public or voucher housing in each year between 1997 and 2010. Our analysis makes use of the individual- and household-level files, which include indicators of housing type (public or voucher), identifiers for housing authorities and projects, as well as some individual- and household-level demographic information. HUD provides a public use summary of these data through the HUDUSER web tool, which we use to calculate PHA-level characteristics.

Data from the LEHD program are based on two sources provided by states on a quarterly basis: (1) unemployment insurance (UI) wage records, providing the earnings of each worker at each employer, and (2) employer account reports providing establishment-level data, also known as the Quarterly Census of Employment and Wages (and formerly as the ES-202 program). ${ }^{14}$ The state-provided data cover more than $95 \%$ of wage and salary civilian jobs, including both private sector and state and local government workers. Some omissions remain, including the armed forces, earnings through self-employment, the postal service, family workers, federal workers, and some non-profit and agricultural workers (U.S. Bureau of Labor Statistics 1997, 2017). Nevertheless, the LEHD earnings data enable us to track a large set of children into adulthood and measure their earnings and employment outcomes as well as these outcomes for the parents of these children. ${ }^{15}$ The coverage extends from the beginning of state reporting through the last quarter of $2016 .{ }^{16}$

Another strength of our data is our ability to track the residential location of households who leave subsidized housing. We do this using two sources of data. First, we use a measure of annual residential location from the Composite Person Record (CPR), a Census Bureau file created

\footnotetext{
${ }^{14}$ The LEHD program, a partnership that has been established between the Census Bureau, all 50 states, the District of Columbia, and the U.S. Office of Personnel Management, produces public use data tabulations that are widely used by state and local governments such as: Quarterly Workforce Indicators, LEHD Origin-Destination Employment Statistics (LODES), and Job-to-Job Flows. For a description of the LEHD Infrastructure Files, see Abowd et al. (2004). For a description of files available in the Federal Statistical Research Data Centers, see Vilhuber (2018).

${ }^{15}$ Specifically, we measure outcomes for the head of households as identified in the HUD-PIC data. Most children (92\%) grow up in single-parent households in the HOPE VI sample.

${ }^{16}$ We code earnings as missing if the state in which their project is located was not yet reporting in the LEHD. However, the vast majority of states are reporting to the LEHD by 2005, which is the earliest year in which we measure age 26 earnings for the children. For the small fraction of children who have missing age 26 earnings, we impute these values using earnings from later years. Specifically, we use a panel of non-missing earnings data for all children between ages 18 and 30 to estimate a regression of annual earnings on an individual fixed effect and a third order polynomial in age interacted with gender. We use the estimates to impute missing earnings data at ages 18-26.
} 
from several federal administrative datasets, which begins in $1999 .{ }^{17}$ We identify a residence census tract for each child and adult from 1999-2010 where available (approximately 10\% of children are missing a CPR residence in each year). Second, we use responses from the 2010 Decennial Census to identify where individuals lived in April 2010. These responses provide an additional data source covering geographic residence of each individual, and also allow us to determine whether that individual is incarcerated in 2010.

We also draw on a number of different publicly available data sources. Most importantly, we characterize the neighborhoods in which individuals live and projects are located using a number of different files including: census tract-level characteristics drawn from the 1990, 2000, and 2010 Decennial Censuses and five-year-average data from the American Community Survey collected between 2008 and 2012; ${ }^{18}$ county-level unemployment rates from the U.S. Bureau of Labor Statistics' Local Area Unemployment Statistics program; area median income and characteristics of PHAs in 1997 from HUD USER; the number of jobs per census tract in 2010, by workplace and residence, from LODES; school proficiency and jobs proximity indexes constructed using data from 2013-2014 and provided through HUD Open Data (the job proximity index is based on LODES); land areas as well as crosswalks between various measures of geographies from the U.S. Census Bureau's Geography Relationship Files; and the Census Bureau Gazeteer files to measure the latitude and longitude of the centroid of census tracts. ${ }^{19}$ We use the Consumer Price Index-Urban to convert all dollar amounts into 2000 dollars.

\subsection{Integration and Sample Selection}

Our sample construction begins by using the HUD-PIC records to identify children between the ages of 10 and 18 who lived in public housing between 1997 and 2001. The range of years is selected because 1997 is the earliest year when reliable HUD microdata are available and 2001 is the date of the last HOPE VI demolition. ${ }^{20}$ The age range is chosen to allow us to observe earnings up through age 26 for all children in the sample. ${ }^{21} \mathrm{We}$ choose to focus on age 26 earnings

\footnotetext{
${ }^{17}$ The LEHD uses the CPR for imputation models and for the residence component of the LEHD Origin-Destination Employment Statistics (LODES) data (for more information on the sources contributing to the CPR, see Graham et al. 2017).

${ }^{18}$ Obtained from the National Historical Geographic Information System (NHGIS) from IPUMS; see Ruggles et al. (2019).

${ }^{19}$ In a small number of cases, neighborhood-level data are missing for certain variables. In order to avoid changes in the sample composition based on the variables used in the analysis, we impute using higher levels of geography. For example, if a variable is missing for a given census tract, we impute the value with county-level value.

${ }^{20}$ As discussed later in this section, we set the "demolition date" two years prior to the award date.

${ }^{21}$ There is one cohort of children, 10-year-olds who appear in public housing in 2001, for whom we do not observe
} 
in our main results since most children will have completed their education by this date and work by Chetty et al. (2014) finds that outcomes measured at this age are strongly predictive of laterlife measures of labor market success. We then attach data from the LEHD, CPR and 2010 Decennial Census to each record from the HUD-PIC data. ${ }^{22}$ An analogous dataset is constructed using the household heads of the children in the sample.

We construct a dataset of public housing projects that describes characteristics of the residents and the neighborhoods in which they are located. To identify the set of projects that received a HOPE VI demolition grant, we start from publicly available data that lists all $285 \mathrm{HOPE}$ VI demolition grant awards. ${ }^{23}$ We make several sample restrictions to the full list of projects to exclude those that are not well-suited for our study design (such as excluding senior housing). These sample restrictions, described in Table A.1, reduce the analysis sample to about 160 projects that received HOPE VI demolitions awards. ${ }^{24}$ Implementing a similar set of restrictions produces a sample of about 8,800 non-HOPE VI projects. ${ }^{25}$

Our primary analysis dataset combines the project- and individual-level data to create a file in which the unit of observation is at the individual-year level, where an individual will appear in the sample for every year that they appear in public housing. We define the "reference year" as the year in which the individual appears in public housing. We drop individual-year observations that appear in the HOPE VI projects in years in which the demolition did not occur whereas we retain all observations from non-HOPE VI projects. ${ }^{26}$ Thus, the reference year for the HOPE VI sample

age 26 earnings because our earning data are only available through 2016. For this cohort, we use observed earnings up through age 25 to impute their earnings at age 26. Specifically, we use a panel of non-missing earnings data for all children between ages 18 and 30 to estimate a regression of annual earnings on an individual fixed effect and a third order polynomial in age interacted with gender. We use the estimates to impute missing earnings data at age 26.

${ }^{22}$ Individuals are identified by a "Protected Identification Key" (PIK) generated by the Census personally identified information, allowing us to attach LEHD data to other data sources. PIKs are linked to approximately $98 \%$ of person records in the HUD-PIC member file for our study period and we drop the $2 \%$ of individuals that are not assigned a unique PIK.

${ }^{23}$ For the HOPE VI demolition grant list, see: HOPE VI DEMOLITION GRANTS: FY 1996 - 2003 (available at https://www.hud.gov/sites/documents/DOC_9890.PDF, dated October 2004).

${ }^{24}$ Throughout the paper we often report rounded numbers to limit risk of disclosure.

${ }^{25}$ Specifically, based on the restrictions defined in Table A.1, we apply the following sample restrictions to the nonHOPE VI projects: 1, 5, 6, and 7. Data from HUDUSER indicate that in 1997 there were about 13,400 projects in the U.S. (excluding territories) and about 10,100 projects that were within our size range (between 15 and 3,000 occupied units) that were not senior citizen housing. Thus, even though we lack data on some PHAs that participated in the Moving To Work (MTW) demonstration, our sample appears to cover most of the comparable public housing projects. ${ }^{26}$ We drop projects that received a HOPE VI Revitalization grant but did not receive a HOPE VI Demolition grant, as households in these projects were treated by a different, but closely related program. For the non-HOPE VI sample, we drop individual-year observations who previously appeared in a HOPE VI project. This restriction prevents us from using individuals who moved out of HOPE VI projects and into other public housing projects as control 
is simply the year of the demolition. This produces a sample with 1,682,000 child-year observations and 1,023,000 household head-year observations.

To identify treated individuals, we need to determine who was living in the project at the time of the demolition. However, identifying the timing of the demolition is complicated by the fact that the PHA may have started to move households out of the project prior to the physical demolition of the building. To address this possibility, we classify households as treated if they resided in a HOPE VI project two years prior to the award date. ${ }^{27}$ To simplify language, we refer to the two years prior to the award date as the year in which the demolition occurred. We view this definition of timing as conservative as it minimizes the chances that our estimated treatment effects are contaminated by selection out of the project prior to the demolition while potentially underestimating the effect if the demolition does not occur until a later time. To evaluate this definition, Figure 1 presents changes in project size relative to this demolition date. ${ }^{28}$ The figure shows similar trends in project size for HOPE VI and non-HOPE VI projects prior to demolition, with HOPE VI projects declining in size for several years thereafter.

Another related issue apparent from Figure 1 is that some of the projects were only partially demolished. While a substantial portion of the households in HOPE VI projects were forced out within five years of the demolition, our sample does include some households who resided in undemolished units and remained in their original housing units. We include these households in the sample as our view is that they are still "treated" by the program since the demolition could have affected the people or characteristics of the neighborhood in which the HOPE VI project was located. ${ }^{29}$

\section{Empirical Strategy}

Our primary goal is to estimate the average effect of HOPE VI demolitions on young adult (age 26) labor market outcomes for children affected by the program - the average treatment effect

\footnotetext{
observations.

${ }^{27}$ Because the HUD-PIC data start in 1997, any HOPE VI projects that have an award date prior to 1999 are assigned a demolition year of 1997. The decision to retain the early awardees is in part motivated by reports that there were longer delays between grant awards and demolitions for these projects (GAO 2003). In Appendix B we show that our results are robust to how we treat projects that received HOPE VI grants prior to 1999.

${ }^{28}$ We measure changes in project size using the number of occupied units in the HUD-PIC household file.

${ }^{29}$ Indeed, in Section 5 we find that the neighborhood in which the project was located is affected in important ways by the demolitions. Furthermore, we find no evidence that the impacts on adult earnings are different for complete versus partial demolitions (see Appendix B).
} 
on the treated. The challenge is that, by design, the projects demolished under HOPE VI were systematically different from those that were not. This is readily apparent from Table 1, which presents the mean and standard deviations of baseline characteristics for projects and residents of HOPE VI and non-HOPE VI projects as well as the differences between two samples. Along almost every observable dimension, children growing up in HOPE VI projects are more disadvantaged. For example, HOPE VI projects are in census tracts with $52 \%$ higher poverty rates, the residents have $20 \%$ lower total annual household income and are almost $50 \%$ less likely to have a married head of household.

Given these pronounced observable differences and the lack of experimental variation, our empirical strategy aims to estimate causal impacts by accounting for observable baseline differences between HOPE VI and non-HOPE VI projects. We argue that this is a reasonable approach in our context because the number of distressed, eligible projects greatly exceeded the number of HOPE VI awardees and our data infrastructure enables us to observe and characterize the conditions in nearly all public housing projects in the U.S. Thus, there is a large sample of nonHOPE VI projects that are informative of what would have happened to the residents of HOPE VI projects had there been no demolitions. In order to estimate the causal impacts of the Demolition program, we employ the stratification with regression estimator proposed by Rosenbaum and Rubin (1983, 1984) and discussed at length in Imbens and Rubin (2015) and Imbens (2015). The method combines features of both matching and regression in the following steps: (1) nearestneighbor matching to trim the sample, (2) groups similar observations into distinct strata based on an estimated propensity score, (3) estimates strata-level treatment effects using Ordinary Least Squares (OLS) regressions with controls within strata, and (4) calculates aggregate treatment effects as a weighted average of the stratum-level estimates.

There are three principal advantages of the stratification with regression estimator over the more traditional OLS estimator. First, trimming the sample and using the stratification structure helps us relax the linear functional form assumptions implicit in OLS. As a rule of thumb, linear regression techniques will tend to be sensitive to the specification when the value of normalized differences between the treatment and control groups exceed one-quarter (Imbens and Woolridge 2009). ${ }^{30}$ Table 1 demonstrates that many important baseline variables have normalized differences

\footnotetext{
${ }^{30}$ Let $\bar{x}_{d}$ and $s_{d}$ be the mean and standard deviation of the variable $\mathrm{x}$ for the HOPE VI $(\mathrm{d}=1)$ and non-HOPE VI $(\mathrm{d}=0)$ samples, respectively. Then the normalized difference is defined as $\left(\bar{x}_{1}-\bar{x}_{0}\right) / \sqrt{\left(s_{1}^{2}+s_{0}^{2}\right) / 2}$.
} 
that exceed this threshold. ${ }^{31}$ Second, many choices on how to adjust for observable differences between HOPE VI and non-HOPE VI projects are governed by the data, which helps mitigate concerns that the choice of specification is influenced by ex-post analysis of results. Third, the stratification with regression methodology presents a number of ways in which we can evaluate the plausibility of the identifying assumptions, some of which are specific to the method and have no clear analogue under OLS. These are discussed in Section 5.3.

Construction of the strata is implemented in three steps. First, we trim the sample of nonHOPE VI projects to reduce the observable differences between the HOPE VI and non-HOPE VI samples. To do so, we start with a project-level dataset that includes all projects after imposing the restrictions mentioned in Section 3. ${ }^{32}$ We use a project-level, as opposed to an individual-level dataset because the treatment is assigned at the project-level. For each HOPE VI project, we use nearest neighborhood matching to identify and retain the five nearest neighbors among the nonHOPE VI projects. Matching is conducted with replacement; distance is measured using the Euclidean distance metric based on observable project and neighborhood characteristics (see Appendix $\mathrm{C}$ for list of variables used in matching); and we require exact matching on the size (large or small) of the PHA. The resulting dataset, which we refer to as the matched sample, contains all 160 HOPE VI projects and a subsample of 570 matched non-HOPE VI projects, which we refer to as control projects.

We thus drop non-HOPE VI projects that are fundamentally different and unlikely to be informative of counterfactual outcomes for HOPE VI residents. The dashed line in Figure A.2 illustrates the success of this trimming by presenting the distribution of the normalized differences of all baseline variables in the matched sample. The differences are much smaller relative to those calculated in the full sample with nearly all smaller than one-quarter. The final three columns of Table 1 make a similar point by presenting summary statistics and difference measures for HOPE VI and matched controls for a subset of important baseline variables. This step does not reduce the external validity of the estimates since we retain all HOPE VI projects and our goal is to estimate the average treatment effect on the treated.

\footnotetext{
31 The solid line in Figure A.2 makes a similar point by presenting the distribution of the normalized differences for all baseline variables calculated on the full sample.

32 Project-level characteristics are measured in the year of the demolition for HOPE VI projects, whereas for nonHOPE VI projects they are equal to the average of observed values between 1997 and 2001.
} 
In the second step, we estimate a project-level propensity score defined as the probability that a project receives a HOPE VI Demolition grant, conditional on observable characteristics. To determine the covariates included in the propensity score model, we use a data-driven method described by Imbens and Rubin (2015). Specifically, we start by estimating a logistic regression of receipt of HOPE VI on a set of covariates that we think are important for predicting treatment (average household income and the proportion of household heads who are black non-Hispanic). Next, we estimate a separate logistic regression for each baseline variable that we consider adding to the model and calculate the log likelihood for each logistic regression. If the value of the $\log$ likelihood ratio test statistic for a given set of covariates is larger than it is for the models with the other potential covariates and sufficiently greater than the initial log likelihood, then we include the covariate in the model. ${ }^{33}$ We iteratively apply this procedure until no more covariates are selected. We then create interaction terms between all the selected covariates and repeat this process to determine which second-order terms to include in the model. Figure 2 plots the distribution of the linearized estimated propensity score for HOPE VI and control projects. ${ }^{34}$ The figures indicate that there is good overlap between the estimated propensity scores of the treated and control projects.

In the third step we use a data-driven method to group projects into distinct strata based on the estimated propensity score. We start by separating the projects into two strata based only on PHA size (small and large). This distinction is motived by the fact that HUD differentiated between these PHAs in the application process. However, it also has the added benefit of avoiding comparisons between individuals who reside in fundamentally different economic environments (e.g., a comparison of someone living in a rural county to an individual living in major metropolitan area). We then expand the number of strata for each initial large- and small-stratum. The adequacy of the existing strata is assessed by calculating a t-statistic for each stratum where the null hypothesis is that the average value of the estimated linearized propensity score is the same for the treated and control projects in that stratum. If the null hypothesis is rejected (i.e. the absolute value of the t-statistic exceeds 1.645), then the stratum is split into two new strata by

\footnotetext{
${ }^{33}$ We include additional first-order (second-order) terms only if the likelihood ratio statistic for the test of the null hypothesis that the additional covariate is equal to zero exceeds 2.5 (4.21).

${ }^{34}$ As a confidentiality protection measure, we Winsorize each distribution at the $5^{\text {th }}$ and $95^{\text {th }}$ percentiles, which overstates the lack of overlap at the tails of the distribution.
} 
grouping projects above and below the median linearized propensity score. ${ }^{35}$ The newly generated strata are required to have at least $3 \mathrm{HOPE} \mathrm{VI}$ and control projects and 50 total projects in order to prevent issues related to small sample sizes in the analysis. ${ }^{36}$ The process is then repeated until either the null hypothesis of no difference between treatment and control projects in the linearized propensity score is not rejected for any stratum, or splitting the stratum at the median treatment project's linearized propensity score would result in too few projects in one of the newly generated strata. This process divides the sample into seven distinct strata. On average, each stratum contains about 18,000 unique children from 100 different projects, 15\% of whom reside in HOPE VI projects. The boundary points of the strata are depicted by the vertical lines in Figure 2 and Table A.2 presents the sample size within each stratum.

This procedure does an excellent job of eliminating differences in observable characteristics between control and treatment groups within each stratum. To demonstrate this point, we regress 92 different baseline variables on an indicator for HOPE VI within each of the seven strata and calculate a t-statistic to summarize the differences between control and treatment observations (standard errors are clustered at the project level). We plot the distribution of the absolute value of the resulting 644 t-statistics in Figure A.3 and compare it to the distribution one would expect from the absolute value of t-statistics from a standard normal distribution. The figure illustrates that, if anything, there is more balance within stratum than would be expected from random assignment. Table A.3 provides a more detailed view by presenting the proportion of test statistics that have a p-value of less than 0.10 for neighborhood-, project- and individual-level characteristics. If balance were good, we would expect that the share of significant test statistics would be approximately $10 \%$. For the most part, we find that this pattern applies. For example, column 6 of Table A. 3 suggests that only $12 \%$ of the 276 p-values calculated within the large PHA sample had a p-value of less than 0.10 and only $6.2 \%$ of 368 p-values calculated within the small PHA sample had a p-value of less than $0.10 .{ }^{37}$

An advantage of this methodology is that many of the choices about how to adjust for observable differences between HOPE VI and non-HOPE VI projects are determined by the data. However, the method does depend on six tuning parameters, which must be defined by the

\footnotetext{
${ }^{35}$ Let $\mathrm{p}$ denote the propensity score, then the linearized propensity score is defined as $\ln (\mathrm{p} /(1-\mathrm{p}))$.

${ }^{36}$ We require 50 total projects in each stratum because we cluster standard errors at the project level.

${ }^{37}$ Without making any adjustments for multiple hypothesis testing, we should observe slightly more than $10 \%$ of tests rejected at the $10 \%$ level.
} 
researcher. ${ }^{38}$ We chose a set of tuning parameters that robustly eliminates baseline differences between HOPE VI and control projects within strata. ${ }^{39}$ There are two important considerations to note here. First, the criteria used for selecting tuning parameters are only based on how well the method eliminates observable differences between HOPE VI and control projects and do not use the outcome variables. Thus, we avoid concerns of specification search. Second, in practice our main findings are robust to alternative choices of tuning parameters (see Appendix B).

Using the stratification structure, we implement our estimator in two steps. First, we separately estimate the following OLS specifications within each of the strata:

$$
\text { \{Eq. 1\} } y_{i t p s}=\alpha_{b}+D_{p} \delta_{b}+X_{i t p s} \beta_{s}+\varepsilon_{i t p s}
$$

where $y$ is a labor market, neighborhood, or household outcome; $i$ is the individual; $t$ is the year in which that individual appears in public housing; $p$ is the project; $s$ is the stratum the project was assigned to in the first stage; $D$ is an indicator equal to one if the project received a HOPE VI demolition award; $X$ is vector of observable individual-, household-, project-, and neighborhoodlevel characteristics; and $\varepsilon$ is an error term which we cluster at the project level. ${ }^{40}$ Because the specifications are run within each stratum, all of the estimated coefficients are stratum-specific.

All specifications include controls for the year in which the individual appears in public housing (with the HOPE VI individuals only appearing in one year), and a standard set of projectlevel controls that include characteristics of the project (average total income of resident

\footnotetext{
${ }^{38}$ These parameters are: (1) the number of matches to use when trimming the sample, (2) the threshold for the likelihood ratio test to include first-order terms for the estimation of the propensity score, (3) the threshold for the likelihood ratio test to include second-order terms for the estimation of the propensity score, (4) a threshold for the test statistic used to determine whether the estimated propensity scores of control and treated projects are sufficiently similar within strata, (5) the minimum number of control projects that must be included in each stratum and (6) the minimum number of treated projects that must be included in each stratum. We view the first three tuning parameters as both the most consequential, since they determine which projects serve as controls for each HOPE VI project, and the most likely to require values specific to applications that differ in number of observations and heterogeneity within the sample. Thus, we use standard values for the fourth through sixth tuning parameters but select "optimal" values for the first through third parameters.

${ }^{39}$ To do this, we implement the stratification 33 different times using different values of the number of matches $(3,5$ or 7) and different values of the second and third tuning parameter. (As a rule of thumb, Imbens and Rubin (2015) find 1.00 and 2.71 work well for the values of the second and third tuning parameters. We vary the value of the second tuning parameter from 1.0 to 6.0 and set the value of the third tuning parameter to 1.71 higher than the second.) We then create a score for each iteration based on the resulting balance of all baseline covariates across HOPE VI and control observations. We find balance is achieved most robustly when using five matches. Thus, we opt to use the specification that delivers the best balance of baseline covariates (lowest-ranked score) when using five matches.

${ }^{40}$ There are a small number of cases in which the outcome variable is missing. To avoid disclosure issues related to releasing results from multiple sample, we impute these missing values with the mean value in the control group and then include an interaction between an indicator for this imputation and treatment status in the regression. In this way imputed values do not contribute to the identification of the treatment effect. In unreported results we estimate all specifications with missing data without this imputation and confirm that the results are not materially different.
} 
households, proportion black non-Hispanic, and proportion of household heads that are female); area median income in 1990; characteristics of census tract in 1990 (proportion on public assistance, median income, and poverty rate); and the county-level unemployment rate in $1996 .{ }^{41}$ The standard vector of individual-level covariates included in the specifications estimated on the child-level dataset includes the interaction between sex and mutually exclusive race/ethnicity categories (black non-Hispanic, white non-Hispanic, Hispanic, and other race or race not specified non-Hispanic); the number of dependents in the household; household size; an indicator for disability; a fixed effect for age at the time of appearing in public housing; an indicator for whether the head of household has a disability; an indicator for whether the household head is female; the marital status of head of household; the age of the head of household, and total household income. ${ }^{42}$ While individuals from HOPE VI projects only appear once in the sample, individuals from control projects may appear multiple times in the sample with an observation for each year they appear in public housing between 1997 and 2001. Nearly all of these individuals appear in the same project and thus clustering standard errors at the project level allows us to take these "duplicate" observation into account when calculating standard errors with each stratum. ${ }^{43}$

The stratum-specific treatment effects are then aggregated across strata, using the stratum's share of the total of treated individuals as weights. Let $N_{t s}$ be the number of treated individuals in stratum $s$ and $N_{t}$ be the total of treated individuals across all strata including both the large and small PHA groups. The weight for each stratum is given by $w_{s}=\frac{N_{t s}}{N_{t}}$, and the estimate of the average treatment effect on the treated, $\hat{\delta}^{a t t}$, and the corresponding standard error, $s e\left(\hat{\delta}^{a t t}\right)$, are given as:

$$
\begin{gathered}
\{\text { Eq. } 2\} \quad \hat{\delta}^{a t t}=\sum_{s=1}^{S}\left(\widehat{\delta}_{s} * w_{s}\right) \\
\{\text { Eq. } 3\} \quad s e\left(\hat{\delta}^{a t t}\right)=\sqrt{\sum_{s=1}^{S}\left(\operatorname{se}\left(\widehat{\delta}_{s}\right) * w_{s}\right)^{2}}
\end{gathered}
$$

where the weighted averages are taken across all $\mathrm{S}$ strata $\left(\mathrm{S}=7\right.$ for the main specification). ${ }^{44}$

\footnotetext{
${ }^{41}$ The large number of individuals within each stratum allows us to include a large set of individual-level controls in our stratum-level regressions. Since the number of projects per stratum is more limited, we are careful to include a smaller number of project-level controls in the regression analysis.

42 The standard vector of individual-level covariates included in the specifications estimated on the household headlevel dataset includes age, race, sex, number of dependents, household size, disability status, marital status, and total household income.

${ }^{43}$ Appendix B shows that our main results are robust to dropping all observations that appear in more than one project and shows that the standard errors are not significantly affected by the presence of these individuals.

44 The implicit assumption needed to construct the standard errors is that observations across strata are independent.
} 
Our methodology will produce unbiased estimates of the average treatment effect on the treated under the Conditional Independence Assumption; conditional on the covariates and stratification in the model, assignment of a HOPE VI demolition is as good as random. While this assumption is not empirically testable, we conduct a number of analyses to assess its plausibility. Our method successfully eliminates observable differences between HOPE VI and control projects, which provides some initial support for the Conditional Independence Assumption. After presenting the main results we discuss other checks intended to assess the validity of the empirical approach.

\section{Results}

\subsection{Long-Run Effects on Children}

Table 2 presents the main finding of the paper. On average, exposure to a HOPE VI demolition led to substantial improvements in the long-run labor market outcomes of the children who resided in those projects. Panel A presents the results pooling across large and small PHAs. Columns 1-4 correspond to the estimates for four different labor market outcomes measured in the year that the child turns 26: the number of quarters worked, an indicator equal to one if earnings are strictly positive in all four quarters, total earnings divided by 1,000, and the inverse hyperbolic sine (IHS) of annual earnings. ${ }^{45}$ All coefficients are estimated using the stratification with regression methodology, and the standard set of covariates used in the stratum-level regressions. We find that, on average, the HOPE VI program increased age 26 earnings by $14.2 \%$, annual earnings by $\$ 622$, the number of quarters worked by 0.057 , and the probability that an individual worked all four quarters by 1.6 percentage points. HOPE VI clearly had important positive impacts on adult labor market outcomes.

While the overall impact of the program was positive, there is heterogeneity across different housing environments. Panels B and C of Table 2 present results separately for large and small PHAs. The positive impacts are generally stronger in large PHAs, with differences that are often economically important in size. For example, the IHS earnings specification suggests a

\footnotetext{
We argue that this is reasonable based on the fact that no project appears in more than one stratum and standard errors are clustered at the project level.

${ }^{45}$ We use the IHS of earnings rather than the more traditional log of earnings because estimated coefficients can be interpreted in the same way as with a log-transformed dependent variable but, unlike with the log of earnings, IHS is defined for zero earnings. The IHS is defined as $\left.\log \left[\mathrm{y}_{\mathrm{i}}+\left(1+\mathrm{y}_{\mathrm{i}}^{\wedge} 2\right)^{\wedge} 0.5\right)\right]$ where $\mathrm{y}_{\mathrm{i}}$ is total earnings for individual $i$ (see Burbidge et al. 1988).
} 
$19.5 \%$ increase in age 26 earnings for children in large PHAs and only a $4.5 \%$ increase for those in small PHAs. ${ }^{46}$ We provide additional evidence below that there is meaningful heterogeneity by PHA size in the effect of the program.

We explore heterogenous effects by child age at the time of the demolition, race, and sex by estimating a model in which the indicator for HOPE VI is interacted with these characteristics. Table 3 presents the resulting estimates for large PHAs. ${ }^{47}$ Column 1 indicates that the impacts of the program are no different for older and younger children. ${ }^{48}$ Specifically, children exposed to HOPE VI when they were 10 years old experienced an earnings gain of $20.5 \%$ while this gain is $18.9 \%$ for 18 -year-olds; a difference that is neither economically or statistically significant. This offers some initial evidence that the impacts of the program are not driven by differences in human capital accumulation from exposure to neighborhoods of varying quality, at least through the exposure model typically considered in this literature (as in Chetty et al. 2016; Chetty and Hendren 2018). Column 2 indicates that males experience significantly larger earnings benefits while column 3 suggests that non-white children also benefit more. While we do not have enough power to estimate a model with the full set of interactions between race and sex, column 4 presents estimates from a specification in which we compare the effects for non-white males to all other children. We find that non-white males appear to be the primary beneficiaries of the program.

\subsection{Short- and Medium- Run Effects for Head of Households}

To better understand the mechanisms through which HOPE VI demolitions affected longterm labor market outcomes, we explore the short- and medium-term effects of the program, starting with housing outcomes for households one, three, and five years after the demolition. In Table 4, column 1 shows that HOPE VI led to a 15 and 18 percentage point reduction in the probability that the household head lives in the same housing project five years after the demolition in large and small PHAs, respectively (relative to $33 \%$ and $28 \%$ of control households remaining in their original project). Column 2 and 3 indicate that HOPE VI pushed households into both

\footnotetext{
${ }^{46}$ The long-run benefits found in large PHAs are robust to measuring earnings at alternative times. Figure A.4 in Appendix A presents estimates of the effect of HOPE VI on the IHS of earnings measured between ages 18 and 26. The effect of the program grows over time, starting around zero at age 18 and rising to about 0.2 by age 23 , after which point the effects stabilize through age 26.

${ }^{47}$ Not surprisingly, we also find little evidence of heterogeneous effects in small PHAs. The one exception is that there is some evidence that white children may have benefited more than non-white children in small PHAs. See Appendix B for details.

${ }^{48}$ In unreported results we also find that the lack of heterogeneous effects by age is robust to estimating alternative specifications that employ project or household fixed effects.
} 
voucher and other public housing with a slightly larger shift into voucher housing. Five years after the demolition, HOPE VI households in large housing authorities are 9.8 percentage points (98\%) more likely to be in voucher housing and 5.9 percentage points $(70 \%)$ more likely to be in a new public housing project; the analogous figures in small housing authorities are 10.7 percentage points $(106 \%)$ and 9 percentage points $(134 \%)$ for voucher housing and new public housing projects, respectively.

Column 4 of Table 4 illustrates that while there is evidence that households were displaced from assisted housing one year after the demolition in large PHAs, HOPE VI did not push households out of subsidized housing in the longer-run. ${ }^{49}$ We emphasize that many households in HOPE VI projects did end up leaving subsidized housing within a five-year period, but that the rate at which they did so was similar in the control group $-48.5 \%$ and $54.9 \%$ of control household heads departed assisted housing within five years in large and small PHAs, respectively. This finding is consistent with other work that finds high rates of turnover in low-quality public housing projects (McClure 2018).

In addition to altering the type of housing, HOPE VI also increased the likelihood of migration to new neighborhoods. Column 6 of Table 4 indicates that HOPE VI increased the probability of moving to a new census tract five years after the demolition by 13.0 and 17.2 percentage points in large and small PHAs, respectively. Column 5 indicates that these moves to new neighborhoods were typically occurring without moves across county boundaries. The HOPE VI-induced residential mobility is therefore extremely local.

Given this increased mobility of HOPE VI households, we examine the average characteristics of the neighborhoods in which they resided between one and five years after the demolition. ${ }^{50}$ Table 5 illustrates that, in both large and small PHAs, HOPE VI did not lead households to move to higher quality neighborhoods as measured by census tract school quality and poverty rate, or to demographically distinct neighborhoods as measured by the share of

\footnotetext{
${ }^{49}$ The category "other public" refers to individuals who appear in the HUD-PIC files but are not in the same project or in voucher housing. The vast majority of these individuals are actually in public housing but there may be a small percentage who participate in the Section 8 Moderate Rehabilitation Program, which is the other assisted housing program covered by the HUD-PIC files. In addition, the category "non-subsidized" refers to individuals who do not appear in the HUD-PIC files. The HUD-PIC files cover both the public housing and voucher programs, which are by far the largest programs subsidizing housing costs for renters. Thus, while there may some households in this group that participate in other subsidized housing programs not covered in the HUD-PIC data, the numbers are likely to be very small.

${ }^{50}$ We find similar patterns if we instead use the timing as in Table 5 and measure characteristics of neighborhoods 1 , 3 , and 5 years after the demolition.
} 
residents that are White non-Hispanic. The estimated impacts on the school proficiency index are not statistically distinguishable from zero and less than $1 \%$ of the magnitude of a control group standard deviation; similarly, while the point estimates for census tract poverty rates are negative in both small and large PHAs, we are unable to reject the null of no effect and they are only around $4 \%$ of the control group mean poverty rate in both PHA size groups. This is partially consistent with existing evidence from Chicago: Chyn (2018) finds evidence of short-term moves to more advantaged neighborhoods, but he also finds that these effects fade quickly over time.

Finally, we estimate the effect of HOPE VI on labor market outcomes for the head of household. Table 6 presents estimates of the impact of the program on the number of quarters worked and the IHS of annual earnings measured five and ten years after the demolition for the heads of household. We find no evidence that HOPE VI improved or depressed labor market outcomes for the parents. Together, none of the results in this section suggest that the long-run benefits for children are driven by measurable improvements in the home or neighborhood environment that would be likely to affect human capital accumulation while young.

\subsection{Assessing the Validity of the Empirical Strategy}

As stated above, our ability to interpret the estimates as causal relies on the Conditional Independence Assumption. While we have previously shown that the methodology does a good job eliminating observable differences between HOPE VI and control projects, it is still possible that the results are biased by unobserved differences or functional form assumptions implicit in the stratum-level regressions. In this section we implement three types of analyses to address these concerns: "pseudo treatment," "pseudo outcome," and "sensitivity/robustness" analyses.

First, we implement a pseudo treatment analysis in which we define a group of projects that were not affected by HOPE VI as pseudo treatment projects. We then estimate pseudo treatment effects by re-implementing the full trimming and stratification with regression method with the pseudo treatment group in place of the true treatment group and omitting the true treatment group from the sample. Estimating null effects for projects that, a priori, should not have systematically different potential outcomes for resident children from comparable projects provides evidence that the methodology is able to adequately correct for baseline differences. This analysis is most convincing if the pseudo treatment projects are, absent exposure to the HOPE VI program, more similar to the true HOPE VI treatment projects than the full set of control projects. Thus, we implement the pseudo treatment analysis using the set of projects that applied for but 
never received funding for the HOPE VI Demolition or Revitalization programs. ${ }^{51}$ Table A.4 presents the estimated effects of the pseudo treatment, which are never statistically different from zero and standard errors are similar in size to those from our main results in Table 2. The results indicate that after the matching methodology is applied to the group of failed applicants, there is no evidence of positive bias. ${ }^{52}$ Thus, the pseudo treatment analysis bolsters confidence in the validity of our methodology.

Second, we implement pseudo outcomes analyses. Here we select a variable measured prior to the demolition, designate it as a pseudo outcome, and re-implement the trimming and stratification process after excluding any variable that is derived from the pseudo outcome from being included in any other part of the matching or regression analysis. For example, if household income were the pseudo outcome, we would implement the matching and estimation of the propensity score without using the average income at the project level. We then use the stratification with regression estimator to estimate a pseudo outcome effect in which the pseudo outcome is the outcome variable and we include the full set of controls (excluding the pseudo outcome). The results from these analyses are displayed in Table A.5. Each row presents the results for one of the 18 pseudo outcomes, with columns 1-3 presenting estimates for the large, small, and pooled samples, respectively. Overall, the results confirm the ability of the methodology to remove differences between HOPE VI and control projects. Column 3 indicates that only 2 of the 18 pseudo outcome estimates are statistically significant when pooling across housing authority sizes. We do, however, reject the null of no pseudo outcome effect for household income. This likely indicates that household income is a critical variable in the matching process for which there is not a close substitute.

\footnotetext{
${ }^{51}$ There were too few failed applicants identified in the public data for only the demolitions program, so we pooled applicants across the two programs. However, given that the two programs targeted a similar group of projects and that the projects look similar along observable characteristics at baseline, we argue that this is an informative exercise. Figure A.5 provides evidence to show that failed applicants had similar observable characteristics to the HOPE VI demolition awardees at baseline. Note that failed applicants were subject to the same set of restrictions as all other non-HOPE VI projects (see footnote 25).

${ }^{52}$ If anything, there appears to be a negative pseudo treatment effect, which could suggest that HOPE VI projects are negatively selected relative to counterfactual projects and our main estimates may provide lower bounds on the true effect of HOPE VI. Alternatively, these negative (statistically insignificant) associations could be explained if the applicant projects were exposed to alternative, less effective programs in place of HOPE VI. The fact that they might have been exposed to other programs complicates the interpretation of the estimated effect of HOPE VI when the failed applicants are included in the set of controls. While we include the failed applicants in our set of potential controls, in practice they make up only small portion of the matched sample used to estimate the main results. Indeed, our results are robust to excluding failed applicants from the set of matched controls.
} 
Third, we assess the robustness of the estimates to alternative variables used in the regression adjustment. Table A.6 presents estimates of the effect of HOPE VI for four different specifications that either (1) use the baseline stratification structure or simply define two strata by large and small PHAs and (2) do or do not include covariates in the model. Column 3 and 4 use the baseline stratification structure but do and do not include covariates in the model, respectively. For large PHAs, the estimated effect of HOPE VI on the IHS of earnings at age 26 is 0.157 without controls compared to 0.195 with controls. ${ }^{53}$ For small PHAs, estimates with and without controls are similarly small across the two specifications (0.005 and 0.045). Thus, once the stratification structure is implemented, the main role of the covariates in the model is to increase precision. This finding suggests that the choice of which covariates are included in the stratum-level regressions and how they are included (functional form) are not driving the results. In addition, the similarity between the standard errors in column 2 and 4 mitigates concerns related to inadequate sample sizes for clustering standard errors at the project level within strata and to individuals in control projects appearing in multiple projects across distinct strata. ${ }^{54}$

\subsection{Mechanisms}

What are the mechanisms through which HOPE VI affected long-run labor market outcomes? In other research that finds long-term labor market benefits of exiting public housing when young, Chyn (2018) and Chetty et al. (2016) find evidence of an exposure model: environment shapes the development of human capital with an influence that is increasing in the duration of exposure and particularly important for young children. However, the evidence presented in Sections 5.1 and 5.2 is inconsistent with the exposure model in our context. Specifically, we find no direct evidence that HOPE VI improved childhood environment by increasing the earnings of parents or improving neighborhood quality along the dimensions typically considered by the literature. Furthermore, we do not find larger impacts for children that were younger at the time of the demolition, a finding that is central to the exposure model. While the evidence suggests a different mechanism than is highlighted in the existing literature, our

\footnotetext{
${ }^{53}$ While the point estimate is smaller in column 3 (the specification that uses the stratification structure without covariate adjustment) relative to column 4 (the baseline specification), the estimate would be statistically significant if the standard error from the main specification were used to conduct the hypothesis test.

${ }^{54}$ Appendix Table A.7 shows that the main results are also robust to using OLS and restricting the sample of control projects to: 1) projects in the same PHA as a HOPE VI project, or 2) projects that applied for but did not receive HOPE VI funding. See Appendix B for details.
} 
results do not conflict with the exposure model findings. Our analysis focuses on older childrenbetween the ages of 10-18 at the time of the demolition - for which prior research has found limited potential for exposure effect-type mechanisms. Additionally, MTO provided assistance for households to facilitate moves to lower poverty neighborhoods and explicitly required moves to lower poverty neighborhoods in the experimental treatment arm. No similar incentives existed for the households affected by the HOPE VI program. It is possible that we would see exposure effects for younger cohorts of children, or if the program at study had included more encouragement for beneficiaries to move to higher quality neighborhoods, as was the case with MTO.

Changes in the exposure to, or involvement in, criminal activity is another mechanism that both motivated the creation of the HOPE VI program and has been explored in the literature on neighborhood effects. While our measures related to crime are admittedly limited, we do not find any evidence that HOPE VI affected the likelihood of incarceration. Following the methodology of Andersson et al. (2018a), we link individuals to the 2010 Decennial Census File to determine whether they reside in an adult correctional facility at the time of the survey. Table A.8 indicates that the effect of HOPE VI increased the probability of being incarcerated in 2010 by 0.001 and 0.005 in large and small PHAs, respectively. These effects are both economically and statistically insignificant. 55

Rather than affecting the environment in which the children grew up, HOPE VI could have affected labor market outcomes by instead influencing where they live as young adults. We investigate this possibility by studying residential outcomes of the children measured in $2010 .^{56}$ As a starting point we estimate a number of specifications in which the outcome variable is an indicator equal to one if the distance between the project and the location of residence in 2010 exceeds some threshold. The results are presented in Figure 3. In both large and small PHAs, HOPE VI pushed children away from the neighborhoods in which their projects were located, but the resulting moves were quite local. About one-half of all children lived within five miles of their

\footnotetext{
${ }^{55}$ In unreported results, we show that this null result also holds when limiting the sample to males, who are at higher risk of being incarcerated.

${ }^{56}$ We focus on 2010 because we are best able to measure residential location by combining data from both the 2010 Decennial Census and the CPR. The children are between the ages of 19 and 31 in 2010 and thus these measures of residential location may not correspond exactly to where children are living when we measure their earnings at age 26. However, we do not think this is a major concern because most children will be in their mid-twenties at this time and, as shown in Figure A.4, the effect of the program in Large PHAs starts at around zero at age 18 but increases to about 0.2 by age 23 , after which point the effects stabilize through age 26 . The longitude and latitude from the internal points of the census tract (the centroid) are from Census Bureau Gazetteer Files for 2010 geography.
} 
project in 2010, and HOPE VI increased the likelihood of moving to a new neighborhood within a 5-mile radius of the project but had no discernable effect on moving farther away. Thus, while HOPE VI induced households to move, it did not increase the likelihood that they moved far from their original locations.

It is possible that HOPE VI could have affected labor market outcomes by dispersing residents and breaking apart peer groups. Such disruptions could be either beneficial or detrimental, depending on the characteristics of the network. To investigate this, we use residential location in 2010 to measure the distance between adult children and each of their former public housing co-residents. We create four variables to characterize network dispersion: the average log distance to all former co-residents and the share of former residents who live within a 1-, 3-, and 5-mile radius. The results, presented in Table A.9, suggest that HOPE VI did not disperse residents geographically in large PHAs. While these are coarse measures, the results provide no evidence that HOPE VI improved labor market outcomes by disrupting peer groups formed in public housing. Note that these results are not inconsistent with those presented in Figure 3 since affected households could have remained spatially close if they moved to a nearby neighborhood after the demolition.

HOPE VI could also have influenced children's subsequent labor supply decisions by affecting the probability that children live in subsidized housing or with their parents as young adults. However, the results in column 3 of Table A.8 indicate that HOPE VI had no detectable effect on the probability of being in subsidized housing in 2010; similarly, columns 4 and 5 show that the program had no detectable impact on living near or with parents.

We do find, however, that the program led to a meaningful change in some of the characteristics of the neighborhoods where the children lived as young adults. We estimate the effect of HOPE VI on six characteristics of the census tract in which the individual resided in 2010 including poverty rate, employment rate, a measure of labor market networks (observed network isolation), and three measures of the geographic proximity to jobs (the log of the ratio of jobs to people, the average commute time and a job proximity index that captures the "the accessibility of a given neighborhood as a function of its distance to all job locations within a [Core-Based Statistical Area]"). ${ }^{57}$ The results, presented in Table 7, illustrate that, within large PHAs, HOPE

\footnotetext{
${ }^{57}$ For a description of the job proximity index see: http://hudgis-hud.opendata.arcgis.com/datasets/jobs-proximityindex. The underlying measure is the same as Shen (1998) and Wang (2007) and is similar to that in Andersson et al.
} 
VI lead to an improvement in the geographic proximity to jobs along all three measures considered. In contrast, there is no evidence that HOPE VI moved children to better neighborhoods in terms of poverty, employment rate, or network isolation. In small PHAs, there is no evidence that HOPE VI improved geographic proximity to jobs, and even some evidence that it led individuals to live in areas with lower job proximity.

Were HOPE VI-induced moves substantial enough to plausibly generate the improvements in job proximity? While these moves tended to be to nearby neighborhoods, moving short distances could still lead to large improvements in job proximity; the housing projects in the sample were often located in neighborhoods that were especially geographically isolated from jobs, even relative to nearby neighborhoods. This can be seen in Figure 4, which presents the average commute time, poverty rate and population density in 1990 (before all demolitions) for housing projects by treatment status (HOPE VI and control), PHA size (large and small), and distance to a sample project (whether HOPE VI or control). In large PHAs, the public housing residents (of both HOPE VI and control projects) had substantially higher commute times, poverty rates, and population densities relative to residents of surrounding neighborhoods. ${ }^{58}$ Thus, it is plausible that even the local moves induced by HOPE VI could have shifted children into neighborhoods with better access to jobs.

HOPE VI neighborhoods were outliers in terms of both job proximity and poverty. An important question then is how the program could have induced moves to new neighborhoods that were better in terms of job accessibility but not poverty. One potential explanation is that neighborhood poverty is more strongly (and negatively) associated with housing prices than job accessibility. For the households participating in public housing, meaningful housing price increases are likely to preclude them from moving to a neighborhood. To assess this possibility, we use publicly available data to identify all counties that contained a HOPE VI project. Within each of these counties we construct population-weighted percentile ranks of neighborhoods based

(2018b), though it uses distance for the impedance function rather than travel time. The values of this underlying measure are percentile ranked with values ranging from 0 to 100 and higher values indicates neighborhoods with better access to jobs. The job proximity index is constructed by HUD using data from LODES (based on LEHD) for 2014. The observed network isolation index measures, for employed residents of a tract, the share of their co-workers who are also neighbors, where high values of this variable could arise if information on job opportunities disseminate through local networks (see Hellerstein et al. 2011 and Hellerstein et al. 2019).

${ }^{58}$ The average commute time is the best available measure of job proximity prior to the demolitions. The job proximity index is not available during this time period since the LEHD data used to construct the measure have limited coverage years prior to 2000 . 
on median rent, average commute time, and poverty rate as measured in 1990. Columns 1-2 of Table A.10 present estimates from bivariate OLS regressions of average commute time on median rent and neighborhood poverty on median rent. There are two key findings from the estimates. First, poverty and median rent are strongly negatively correlated; within a city, neighborhoods with a one percentile higher rank in terms of median rent have a 0.53 and 0.41 percentile lower poverty rate rank in large and small PHAs, respectively. The R-squared values from these regressions are 0.18 (in large PHAs) and 0.11 (in small PHAs). In contrast, there is no evidence that neighborhoods with higher levels of job proximity are more expensive. In large PHAs the Rsquared from a regression of the average commute time rank on the median rent rank is 0.003 , and the point estimate is small, negative (-0.0189), and not statistically distinguishable from zero. ${ }^{59}$ While the average commute time is an imperfect measure of job proximity, the lack of relationship between housing costs and job proximity is robust to using the job proximity index constructed by HUD, which is available only in 2010 (see columns 3-4 of Table A.10). The cross-sectional associations therefore support the idea that while moves to neighborhoods with better job accessibility were likely financially feasible for HOPE VI-affected households, higher housing prices may have made moves to lower poverty neighborhoods more difficult. This is consistent with evidence from of quasi-experimental (Collinson and Ganong 2018; Andersson et al. 2018a), experimental (Patterson et al. 2004; Eriksen and Ross 2013; Jacob, Ludwig, and Miller 2013), and observational (Susin 2002; Carlson et al. 2012) studies on the Voucher program. An important caveat is that homes with similar rents in more job-accessible neighborhoods may be lower quality (e.g. smaller), but absolute housing cost may still be the most relevant decision factor for our sample.

In addition to forcing people to move to new neighborhoods, HOPE VI could have also improved job accessibility for households that remained in their original neighborhood or moved extremely short distances by altering the characteristics of the original neighborhoods themselves. To explore this possibility, we measure the average job proximity index of census tracts within half-mile radius bands from zero to five miles around the project. We then attach these neighborhood-level measures to the child-level dataset and implement the stratification with regression methodology as before to estimate the effect of HOPE VI on the characteristics of these neighborhoods. The results for large and small PHAs are presented in Figure 5. We see no

\footnotetext{
${ }^{59}$ In small PHAs there appears to be evidence that job proximity is negatively related to housing costs.
} 
significant impacts on job proximity in small PHAs at any distance. For large PHAs, HOPE VI produced substantial improvements in the job proximity index for the census tract in which the project was located, but these effects dissipate quickly and there appears to be no impact on neighborhoods located farther than half a mile away. ${ }^{60}$ That the effects dissipate quickly with distance is reassuring since we would not expect the demolition of a public housing project to drastically transform the population or job density in more distant neighborhoods. ${ }^{61}$

To investigate the origins of the effect on these neighborhood-level measures of job proximity, we estimate the effect of HOPE VI on three characteristics of the census tract in which the project was located: the $\log$ of the ratio of jobs to people, the log of the density of jobs, and $\log$ of population density. ${ }^{62}$ The results, presented in Table A.11, imply that, HOPE VI increased the ratio of jobs to people in large PHAs by $22 \%$, and that this impact was driven primarily by a reduction in population density: HOPE VI reduced in population density by $62 \%$, a finding that is statistically significant at the $1 \%$ level. HOPE VI is also associated with a statistically insignificant $4.5 \%$ increase in job density. A reduction in population density will increase job accessibility by reducing the number of competing searchers in the local labor market (more competing searchers lower the job proximity index) as long as the number of jobs in the neighborhood does not also decline. In the case of a public housing demolition, the reduction is for a population likely to compete for a similar set of jobs (Lens 2014; Lens et al. 2019). In small PHAs, we find no effect of HOPE VI on job or population density. This is likely due to the fact that public housing projects typically had far fewer residents in small PHAs, and the demolitions therefore did not displace as many households or lead to meaningful reductions in population density.

The preceding analyses suggest that HOPE VI improved geographic proximity to jobs in large PHAs both by transforming the neighborhood in which the project was located and by moving former residents to new neighborhoods with better accessibility. To investigate the

\footnotetext{
${ }^{60}$ The finding that the neighborhood in which the project was located underwent large changes supports our choice to include all, and not just partial, demolitions in the analysis. Household in units that were not demolished were still treated by the program by changes in neighbors and changes in the existing neighborhood.

${ }^{61}$ The fact that HOPE VI affected both the census tract in which the project was located and census tracts within a half mile radius could reflect the fact that projects may have been located in multiple census tracts though we assign each project to a unique census tract. Other research on HOPE VI has generally found that spillover effects of the demolitions dissipate within a mile (e.g. Sandler 2017).

${ }^{62}$ Density is calculated by dividing the number of jobs (or population) by the land area of the census tract, so both measures use the same land area for normalization. Land area cancels out in the job/population ratio.
} 
quantitative importance of each channel, we estimate specifications that replace the true measure of job proximity with a counterfactual measure that discards all variation due to changes in the HOPE VI neighborhoods. In order to calculate this counterfactual measure, we use the stratification with regression method to estimate the effect of HOPE VI on the job proximity index, limiting the sample to census tracts within a half-mile radius of the original project; note that these are the areas where HOPE VI directly impacted job proximity, as shown in Figure 5. We obtain a predicted value of the job proximity index for HOPE VI neighborhoods in the absence of changes to the original neighborhood by setting all covariates to their true value except for the HOPE VI indicator, which is set to zero instead of one. The counterfactual measure of the job proximity index is equal to this predicted value for all children who resided in HOPE VI projects and still lived within a half-mile of their project in 2010 - i.e. children whose neighborhood job proximity was directly affected by the demolitions-induced changes - and is set to the true value of the job proximity index for all other children. Intuitively, we impute the job proximity for individuals from HOPE VI projects who remained within a half-mile of their original project (and therefore benefitted from changes in the neighborhood of origin) using the job proximity for individuals from observably similar control projects. Any estimated improvements using this counterfactual measure of job proximity will thus be entirely driven by HOPE VI-induced moves to new neighborhoods. We then estimate the impact of HOPE VI on this counterfactual job proximity measure for large PHAs. The original estimates, presented in Table 7, indicate that HOPE VI increased the job proximity index by 2.11 . When the counterfactual value of the job proximity index is used as the outcome variable, this estimated impact falls to 1.16, suggesting that improvements in the neighborhood in which HOPE VI projects were located explain about $45 \%$ of the total impact on the job proximity index in large PHAs. This back-of-the-envelope calculation therefore suggests that, within large PHAs, HOPE VI improved access to jobs by moving children to new neighborhoods and by improving the original neighborhoods that contained the HOPE VI projects, with both channels being quantitatively important.

Improvements in job proximity could affect earnings by reducing job search and/or commuting costs and encouraging individuals on the margin between working and not working to participate in the labor market. Consistent with this hypothesis, we find that an important part of the earnings gains occurs through an extensive margin labor supply response. Using the estimates from Table 2, the control means from columns 1 and 4 indicate that the average working child 
from the control group earns $\$ 3,944$ per quarter whereas column 1 indicates that HOPE VI increased quarters worked by 0.076 . Using the effect on quarters worked and average earnings per quarter in control projects we calculate that the effect on annual earnings would be $\$ 300$ $(3,944 * 0.076=\$ 300)$ if the entire effect were driven by an increase in labor force participation. This is about $57 \%$ of the estimated effect in column 3, suggesting that extensive margin labor supply responses are the main avenue through which the earnings impacts occur.

As discussed earlier, we find no effect of HOPE VI demolitions on earnings for the heads of household. Given that many of these heads of household are single mothers who qualify for public support and have especially high opportunity costs for time supplied in the labor market, a likely explanation for this discrepancy is that the heads of household have higher reservation wages. Figure A.7 presents the distribution of earnings for household heads and the adult children. Consistent with the theory that household heads have a higher reservation wage, there is a hollowing out of the distribution of labor market earnings for household heads relative to the adult earnings of the children in our main sample; household heads are more likely to have zero earnings (48\% compared to $35 \%$ ) and less likely to have low levels of strictly positive earnings (10\% of households heads have earnings in the bottom quartile compared to $18 \%$ of the adult children).

In sum, there are three reasons that support the job accessibility mechanism as an important driver of our main results. First, we find systematic evidence of improvements in measures of job proximity within large PHAs, where differences in job proximity should be larger and more meaningful. Second, the effect on earnings appears to have a substantial extensive margin component, which is consistent with the hypothesis that HOPE VI primarily affected the costs associated with finding a job and not the rewards from work. Third, the difference in the effect of HOPE VI on earnings in large PHAs versus small PHAs is precisely mirrored by the differences of the effects on the various measures of job accessibility. In the next section we expand upon this last point and show that even within the large PHAs the impacts on earnings are largest in places where we would expect job accessibility to be particularly low absent the intervention.

\subsection{Reconciling Different Effects in Different Environments}

Why does HOPE VI produce substantial long-run labor market gains for children living in large but not small PHAs? One possible explanation is that the program interacted in important ways with local environments. In particular, poor geographic access to jobs might affect labor market outcomes more in the worst neighborhoods. Figure 6 presents kernel density plots of the 
average commute time, poverty rate, and population density in 1990 in the census tracts containing projects in the sample, separately by PHA size (large or small) and HOPE VI treatment status. The figure illustrates that prior to the demolitions, projects in large PHAs, regardless of whether they subsequently received a HOPE VI grant, had significantly higher average commute times, poverty rates, and population densities. ${ }^{63}$

Figure 6 also illustrates that there is substantial variation even within the large PHAs in terms of these baseline characteristics of neighborhoods. We make use of this variation by estimating three specifications in which we interact the indicator for HOPE VI with pre-demolition measures of neighborhood average commute time, poverty, and population density. The results for large PHAs, presented in Table 8, suggest that demolitions had stronger effects for projects in neighborhoods that were more densely populated, where commutes were longer, and where the poverty rate was higher in $1990 .{ }^{64}$ The heterogeneity is economically meaningful. For example, the results suggest that HOPE VI increased age 26 earnings by $37 \%$ for children in neighborhoods that had baseline poverty rates one standard deviation above the mean poverty rate among HOPE VI projects. In comparison, children in neighborhoods with poverty rates one standard deviation below the mean only experienced a $10 \%$ increase in earnings.

Together, the heterogeneity in the effect of HOPE VI both across and within large and small PHAs suggests that the program produced larger labor market gains for children originally residing in high-density, high-poverty neighborhoods, with limited job opportunities nearby. Within these communities, HOPE VI improved labor market outcomes both by shifting children into neighborhoods with better job accessibility and by improving the job accessibility of the original neighborhoods. In contrast, the program offered much smaller (or no) benefits to individuals residing in neighborhoods with better job accessibility prior to the demolition.

The treatment effect heterogeneity is also informative for interpreting findings from existing research. As previously discussed, Chyn (2018) and Chetty et al. (2016) both find longterm labor market benefits from exiting public housing when young. However, only Chyn (2018) finds that these benefits extend to older children (older than 13). Our results suggest an explanation

\footnotetext{
${ }^{63}$ Komogorov-Smirnov equality-of-distribution tests confirm that the differences between HOPE VI projects in the large and small PHAs are statistically significant while the differences between the control and HOPE VI projects within large and small PHAs are not statistically different from one another.

64 Table A.11 presents the results for small PHAs. We find no evidence of meaningful interaction effects here, which is not surprising given that we find no significant effect of HOPE VI in this sample in general.
} 
for this discrepancy: Chyn (2018) notes that the projects in his study were in much higher poverty neighborhoods than those in MTO. His sample thus included public housing projects that were much more disadvantaged, located in neighborhoods with limited job accessibility. Thus, moving older children out of these projects produced more immediate labor market gains, whereas no such gains occurred for older children in the context of Chetty et al. (2016). Relatedly, while Anderson et al. (2018a) find that time spent in public and voucher housing when young produces long-term labor market benefits of similar magnitudes, our paper highlights the fact that these average effects mask substantial heterogeneity, and that children in the lowest quality public housing projects may benefit from changes in housing. More broadly, the results from our paper highlight how housing and neighborhood can affect long-term outcomes through a multitude of channels that vary in importance with local context.

\section{Conclusion}

This paper uses administrative data on earnings and participation in subsidized housing to study how the demolition of public housing projects - funded by the HOPE VI demolitions program - affected the long-run earnings of resident children. We find that, on average, exposure to a demolition increased earnings at age 26 by $14 \%$. However, the benefits appear to be driven by children who lived in neighborhoods that were denser, poorer, and farther from jobs prior to the demolition. In terms of potential mechanisms, we find no evidence that HOPE VI improved the home or neighborhood environment that children were exposed to while young. We do, however, find evidence consistent with HOPE VI improving labor market outcomes by increasing the proximity of job opportunities in the neighborhoods in which the children lived as young adults.

Over the past thirty years, federal housing policy has sought to move families living in subsidized housing out of especially disadvantaged neighborhoods. The results in this paper offer evidence that these moves can generate long-term labor market benefits for children. Interestingly, we find that these moves need not occur in early childhood to produce improvements in adult labor market outcomes. ${ }^{65}$ Instead, our findings highlight the important and immediate impact of reducing barriers to young adult employment through increasing the accessibility of formal market jobs.

\footnotetext{
${ }^{65}$ It is important to emphasize that we are not suggesting that these moves are more beneficial than earlier moves to higher quality neighborhoods. We are not able to investigate this in our study as the youngest children exposed to the demolitions are not old enough to measure adult labor market outcomes.
} 
Neighborhoods can affect labor market outcomes through multiple channels, and severely distressed public housing projects can, in some cases, limit job accessibility and discourage labor force participation by creating densely populated neighborhoods with high rates of poverty and a limited number of nearby jobs.

Our results highlight the importance of accounting for the interaction between subsidized housing policies and local context. Much of the research on assisted housing has taken place in a limited set of large metropolitan areas. In the case of public housing demolitions, our results indicate that the long-run labor market benefits found in other work are specific to this setting (at least for older children), which highlights the possibility that resources may be better spent on alternative interventions in less urban and disadvantaged environments. Research has convincingly documented that housing can have important long-run labor market implications but anticipating the effects of potential interventions requires a more complete understanding of the mechanisms. Future research should continue to focus on better understanding how the impacts of housing policies interact with the characteristics of local environments to produce changes in welfare and contribute to the intergenerational transmission of economic outcomes. 


\section{References}

Abowd, John, John Haltiwanger, and Julia Lane. 2004. "Integrated Longitudinal Employee-Employer Data for the United States." American Economic Review 94(2): 224-229.

Andersson, Fredrik, John C. Haltiwanger, Mark J. Kutzbach, Giordano Palloni, Henry O. Pollakowski, and Daniel H. Weinberg. 2018a. "Childhood Housing and Adult Earnings: A Between-Siblings Analysis of Housing Vouchers and Public Housing." NBER Working Paper 22721.

Andersson, Fredrik, John Haltiwanger, Mark Kutzbach, Henry Pollakowski, and Daniel Weinberg. 2018b. "Job Displacement and the Duration of Joblessness: The Role of Spatial Mismatch." The Review of Economics and Statistics 100(2): 203-218.

Burbidge, John B., Lonnie Magee, and A. Leslie Robb. 1988. "Alternative Transformations to Handle Extreme Values of the Dependent Variable" Journal of the American Statistical Association 83(401): 123-127.

Carlson, Deven, Robert Haveman, Tom Kaplan, and Barbara Wolfe. "Long-term earnings and employment effects of housing voucher receipt." Journal of Urban Economics 71, no. 1 (2012): 128-150.

Chetty, Raj and Nathaniel Hendren. 2018. "The Impacts of Neighborhoods on Intergenerational Mobility I: Childhood Exposure Effects." The Quarterly Journal of Economics 133(3): 1107-1162.

Chetty, Raj, Nathaniel Hendren, Patrick Kline, and Emmanuel Saez. 2014. "Where is the land of Opportunity? The Geography of Intergenerational Mobility in the United States." The Quarterly Journal of Economics 129(4): 15531623.

Chetty, Raj, Nathaniel Hendren, and Lawrence Katz. 2016. "The Effects of Exposure to Better Neighborhoods on Children: New Evidence from the Moving to Opportunity Experiment." American Economic Review 106(4): 855902.

Chyn, Eric, 2018. "Moved to opportunity: The long-run effects of public housing demolition on children." American Economic Review 108(10): 3028-3056.

Collinson, Robert and Peter Ganong. 2018. "How Do Changes in Housing Voucher Design Affect Rent and Neighborhood Quality." American Economic Journal: Economic Policy 10(2): 62-89.

Davis, Steven, John Haltiwanger, and Scott Schuh. 1996. "Small business and job creation: Dissecting the myth and reassessing the facts." Small Business Economics 8(4): 297-315.

Eriksen, Michael and Amanda Ross. 2013. "The impact of housing vouchers on mobility and neighborhood attributes." Real Estate Economics 41(2): 255-277.

Gallagher, Megan, and Beata Bajaj. 2007. "Moving on: Benefits and challenges of HOPE VI for children." HOPE VI: Where do we go from here.

Graham, Matthew, Mark Kutzbach, and Danielle Sandler. 2017. "Developing a Residence Candidate File for Use with Employer-Employee Matched Data." U.S. Census Bureau, Center for Economic Studies Discussion Paper 17-40.

Goetz, E. G. 2010. "Desegregation in 3D: Displacement, dispersal and development in American public housing. Housing Studies" 25(2): 137-158.

Hellerstein, Judith K., Melissa McInerney, and David Neumark. 2011. "Neighbors and Co-Workers: The Importance of Residential Labor Market Networks." Journal of Labor Economics 29(4): 659-695.

Hellerstein, Judith, Mark Kutzbach, and David Neumark. 2019. "Labor market networks and recovery from mass layoffs: Evidence from the Great Recession period," Journal of Urban Economics 113.

Imbens G. 2015. "Matching Methods in Practice." Journal of Human Resources 50(2): 373-419.

Imbens, Guido, and Donald Rubin. 2015. Causal Inference in Statistics, Social, and Biomedical Sciences. New York: Cambridge University Press.

Imbens, Guido W., and Jeffrey M. Wooldridge. 2009. "Recent Developments in the Econometrics of Program Evaluation." Journal of Economic Literature 47(1): 5-86.

Jacob, Brian A. 2004. "Public Housing, Housing Vouchers, and Student Achievement: Evidence from Public Housing Demolitions in Chicago." American Economic Review 94(1): 233-258.

Jacob, Brian A., Jens Ludwig, and Douglas L. Miller. 2013. "The effects of housing and neighborhood conditions on child mortality." Journal of Health Economics 32(1): 195-206.

Jones, Roderick W., and Derek J. Paulsen. 2011. "HOPE VI Resident Displacement: Using HOPE VI Program Goals to Evaluate Neighborhood Outcomes." Cityscape: A Journal of Policy Development and Research 13(3): 85-102.

Kain, John F. 1968. "Housing Segregation, Negro Employment, and Metropolitan Decentralization." Quarterly Journal of Economics 82: 32-59.

Kingsley, Thomas G., Jennifer Johnson, and Kathryn Pettit. 2003. "Patterns of Section 8 Relocation in the HOPE VI Program." Journal of Urban Affairs 25(4): 427-47. 
Lens, Michael. 2014. "Employment Accessibility Among Housing Subsidy Recipients." Housing Policy Debate 24(4): 671-691.

Lens, Michael, Kirk McClure, and Brent Mast. 2019. "Does Jobs Proximity Matter in the Housing Choice Voucher Program?" Cityscape 21(1): 145-162.

Ludwig, Jens, Greg Duncan, Lisa Gennetian, Lawrence Katz, Ronald Kessler, Jeffrey Kling, and Lisa Sanbonmatsu. 2013. "Long-term Neighborhood Effects on Low-Income Families: Evidence from Moving to Opportunity." American Economic Review 103(3): 226-231.

McCarty, Maggie. 2005. "HOPE VI: background, funding, and issues. Report No. RL32236, Congressional Research Service." The Library of Congress, Washington, DC.

McClure, Kirk. 2018. "Length of Stay in Assisted Housing." Cityscape 20(1): 11-38.

Mills, Gregory, Daniel Gubits, Larry Orr, David Long, Judie Feins, Bulbul Kaul, Michelle Wood, Amy Jones \& Associates, Cloudburst Consulting, and the QED Group. 2006. The Effects of Housing Vouchers on Welfare Families. Washington, DC: U.S. Department of Housing and Urban Development, Office of Policy Development and Research.

Murphy, LaShonia. 2012. "The Allocation of Funds with HOPE VI: Applicants and Recipients."

National Commission on Severely Distressed Public Housing (NCSDPH). 1992. The Final Report: A Report to the Secretary of Housing and Urban Development. Washington D.C. August.

Oreopoulos, Philip. 2003. "The Long-Run Consequences of Living in a Poor Neighborhood." Quarterly Journal of Economics 118(4): 1533-1575.

Patterson, Rhiannon, Michelle Wood, Ken Lam, Satyendra Patrabansh, and Gregory Mills. 2004. "Evaluation of the Welfare to Work Voucher Program: Report to Congress.” Abt Associates Inc. Cambridge, MA.

Popkin, Susan J., Diane K. Levy, Laura E. Harris, Jennifer Comey, Mary K. Cunningham, and Larry F. Buron. 2004. "The HOPE VI Program: What about the Residents?" Housing Policy Debate 15: 385-414.

Popkin, Susan J., Diane K. Levy, and Larry F. Buron. 2009. "Has HOPE VI Transformed Residents' Lives? New Evidence from the HOPE VI Panel Study". Housing Studies 24(4): 477-502.

Rosenbaum, James E. 1995. "Changing the Geography of Opportunity by Expanding Residential Choice: Lessons from the Gautreaux Program.” Housing Policy Debate 6(1): 231-269.

Rosenbaum, Paul, and D. Rubin. 1983. "The Central Role of the Propensity Score in Observational Studies for Causal Effects." Biometrika 70: 41-55.

Rosenbaum, Paul, and D. Rubin. 1984. "Reducing the Bias in Observational Studies Using Subclassification on the Propensity Score." Journal of the American Statistical Association 79: 516-524.

Ruggles, Steven, Sarah Flood, Ronald Goeken, Josiah Grover, Erin Meyer, Jose Pacas and Matthew Sobek. IPUMS USA: Version 9.0 [dataset]. Minneapolis, MN: IPUMS, 2019. https://doi.org/10.18128/D010.V9.0.

Sandler, Danielle H. 2017. "Externalities of Public Housing: The Effect of Public Housing Demolitions on Local Crime." Regional Science and Urban Economics 62: 24-35.

Shen, Qing. 1998. "Location Characteristics of Inner-City Neighborhoods and Employment Accessibility of LowIncome Workers," Environment and Planning B: Planning and Design 25(3): 345-365.

Smith, Tony E. and Yves Zenou. 2003. "Spatial mismatch, search effort, and urban spatial structure." Journal of Urban Economics 54(1): 129-156.

Susin, Scott. 2002. "Rent vouchers and the price of low-income housing." Journal of Public Economics 83(1): 109152.

Turner, Margery Austin, Mark Woolley, G. Thomas Kingsley, Susan J. Popkin, Diane Levy, and Elizabeth Cove. 2007. "Severely Distressed Public Housing: The Costs of Inaction." Washington, DC: The Urban Institute.

U.S. Bureau of Labor Statistics. 1997. BLS Handbook of Methods. Office of Publications and Special Studies, Washington, DC.

U.S. Bureau of Labor Statistics. 2017. BLS Handbook of Methods. Division of Information Services, Washington, DC. Last modified April 14, 2017.

U.S. Department of Housing and Urban Development (HUD). 2007. HOPE VI Program Authority and Funding History. https://www.hud.gov/sites/documents/DOC_9838. (accessed 19 September 2019).

U.S. General Accounting Office (GAO). 2003. Public Housing: HUD's Oversight of HOPE VI Sites Needs to be More Consistent. US General Accounting Office.

Vilhuber, Lars. 2018. "LEHD Infrastructure S2014 files in the FSRDC.” U.S. Census Bureau, Center for Economic Studies Discussion Papers, CES 18-27r.

Wang, Fahui. 2007. "Job Access in Disadvantaged Neighborhoods in Cleveland, 1980_2000: Implications for Spatial Mismatch and Association With Crime Patterns.” Cityscape 9(3): 95-121. 


\section{Figures}

Figure 1: Changes in Project Size Relative to Year of Demolition

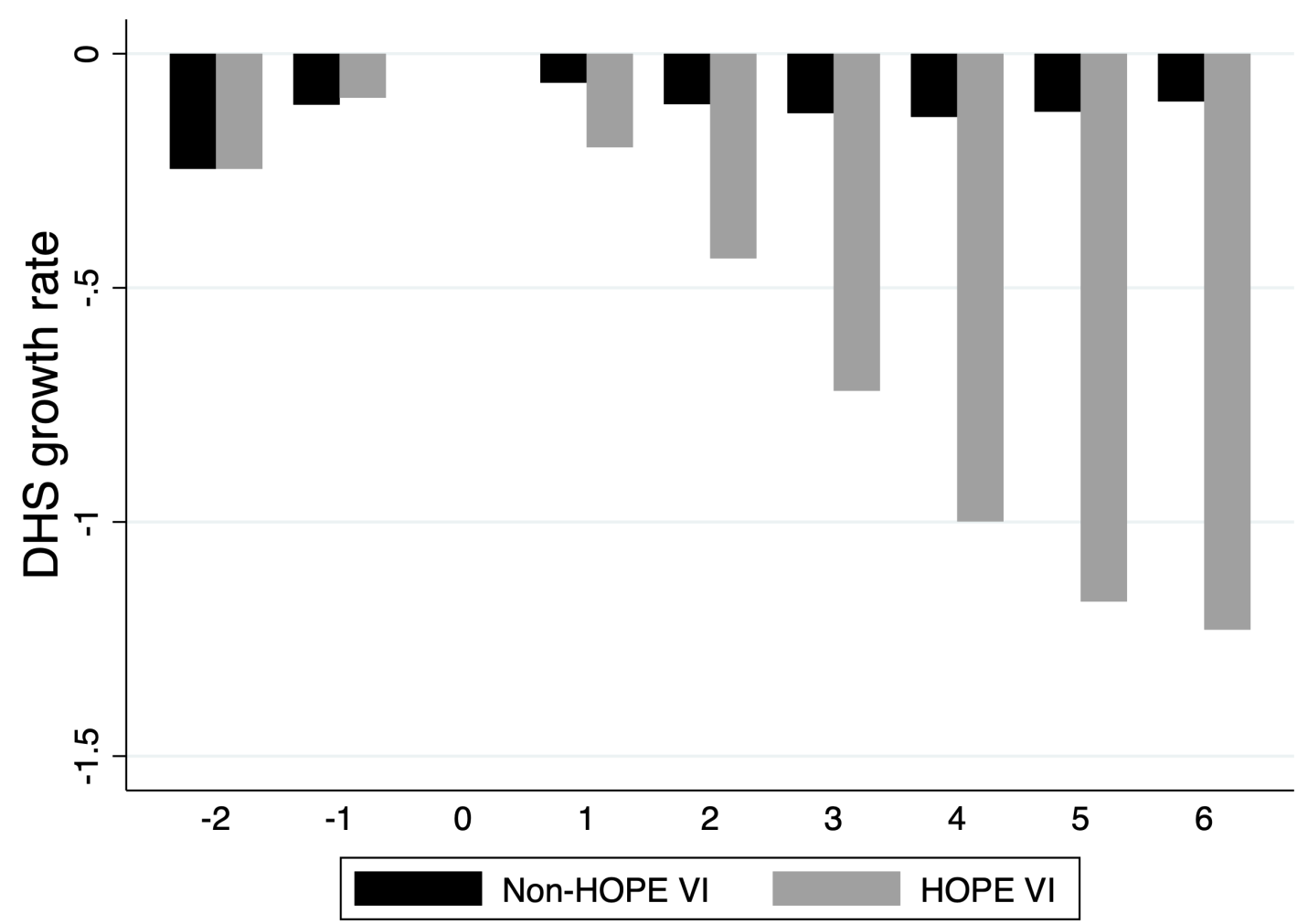

Notes: The figure plots the average DHS growth rate (see Davis, Haltiwanger and Schuh 1996) in project size between the reference year and $\mathrm{x}$ years after the reference year, where $\mathrm{x}$ corresponds to the value on the horizontal axis. The growth rate in project size between year $\mathrm{t}\left(y_{t}\right)$ and year $\mathrm{s}\left(y_{s}\right)$ is defined as: $\frac{y_{t}-y_{s}}{\frac{1}{2}\left(y_{t}+y_{s}\right)}$. For HOPE VI projects, the reference year is the year of the demolition, which is defined as the greater of two years prior to the award year and 1997. Averages are calculated using the child-year dataset, implying that the averages are weighted by project size. Source: Authors' calculations from matched Longitudinal Employer-Household Dynamics, Department of Housing and Urban Development, and Decennial Census files. 


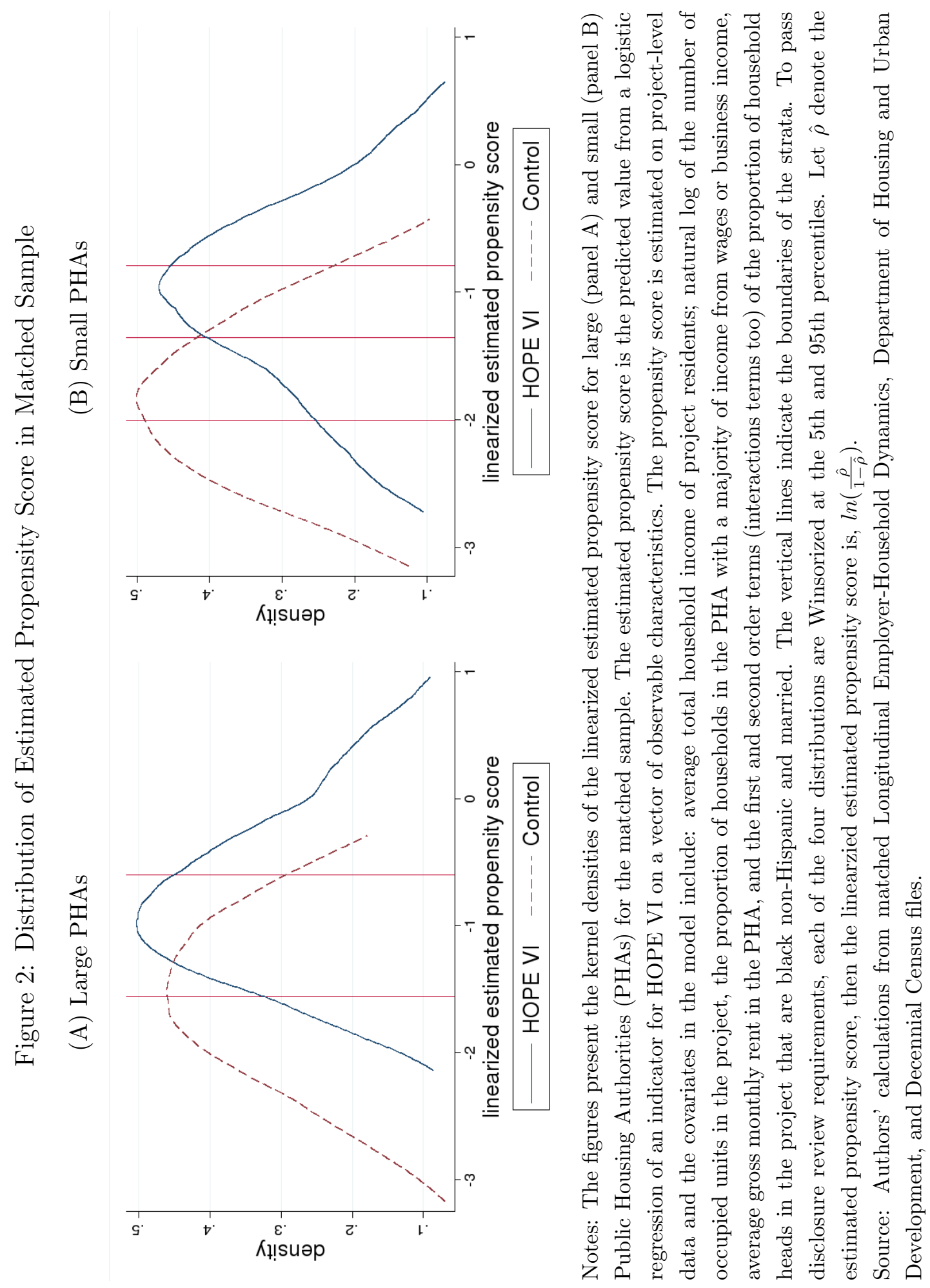




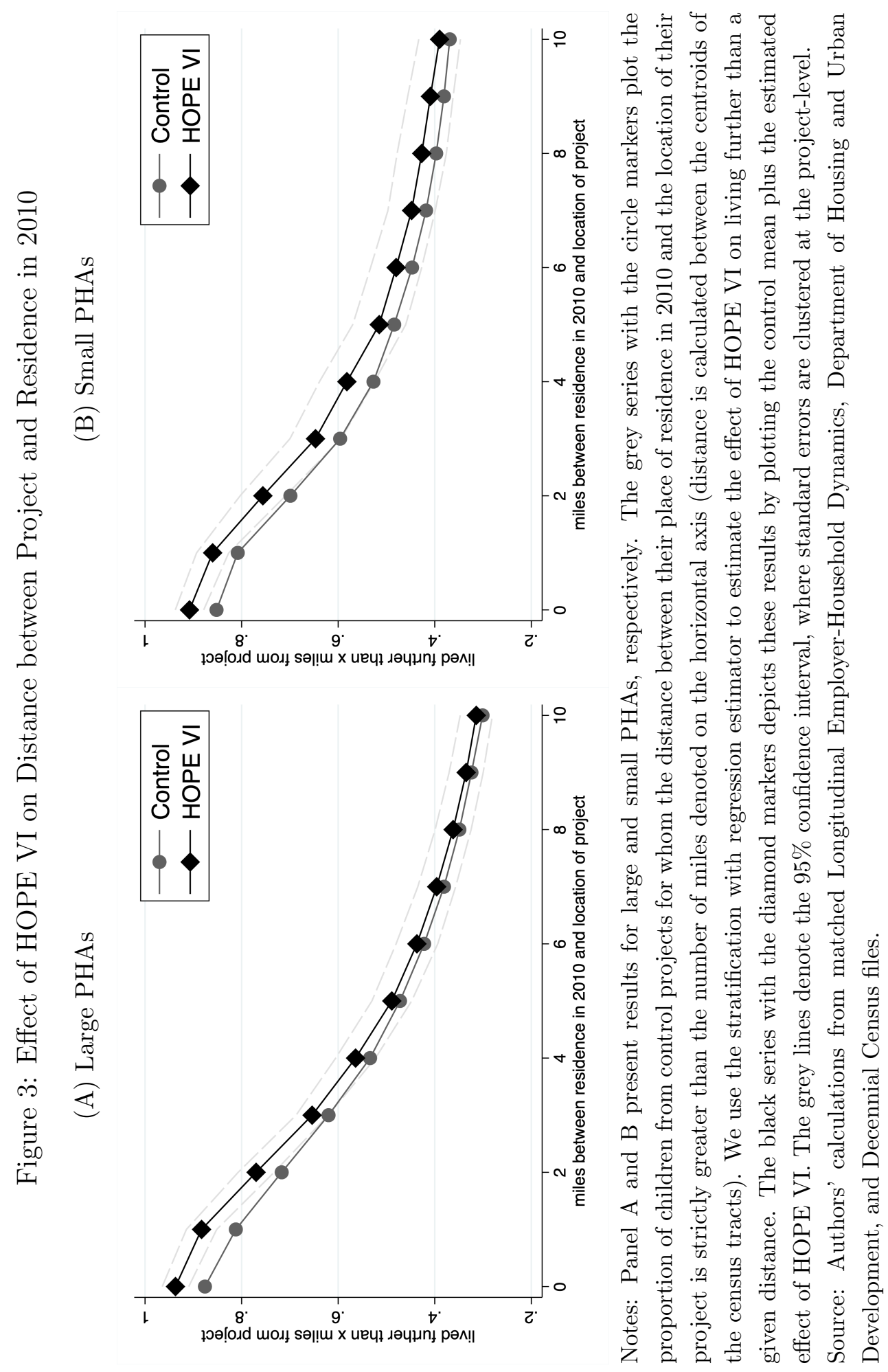




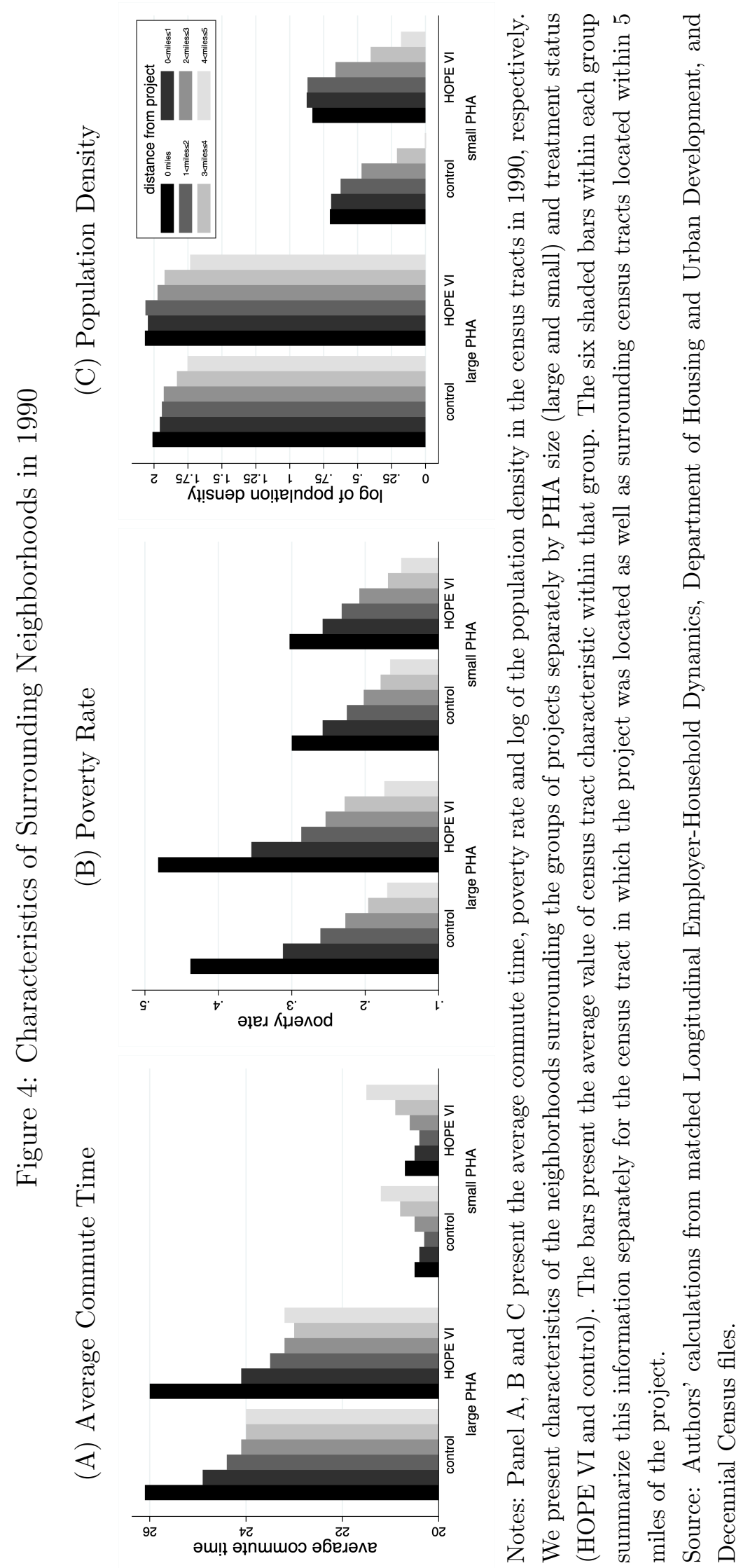


Figure 5: Effect of HOPE VI on Surrounding Neighborhoods

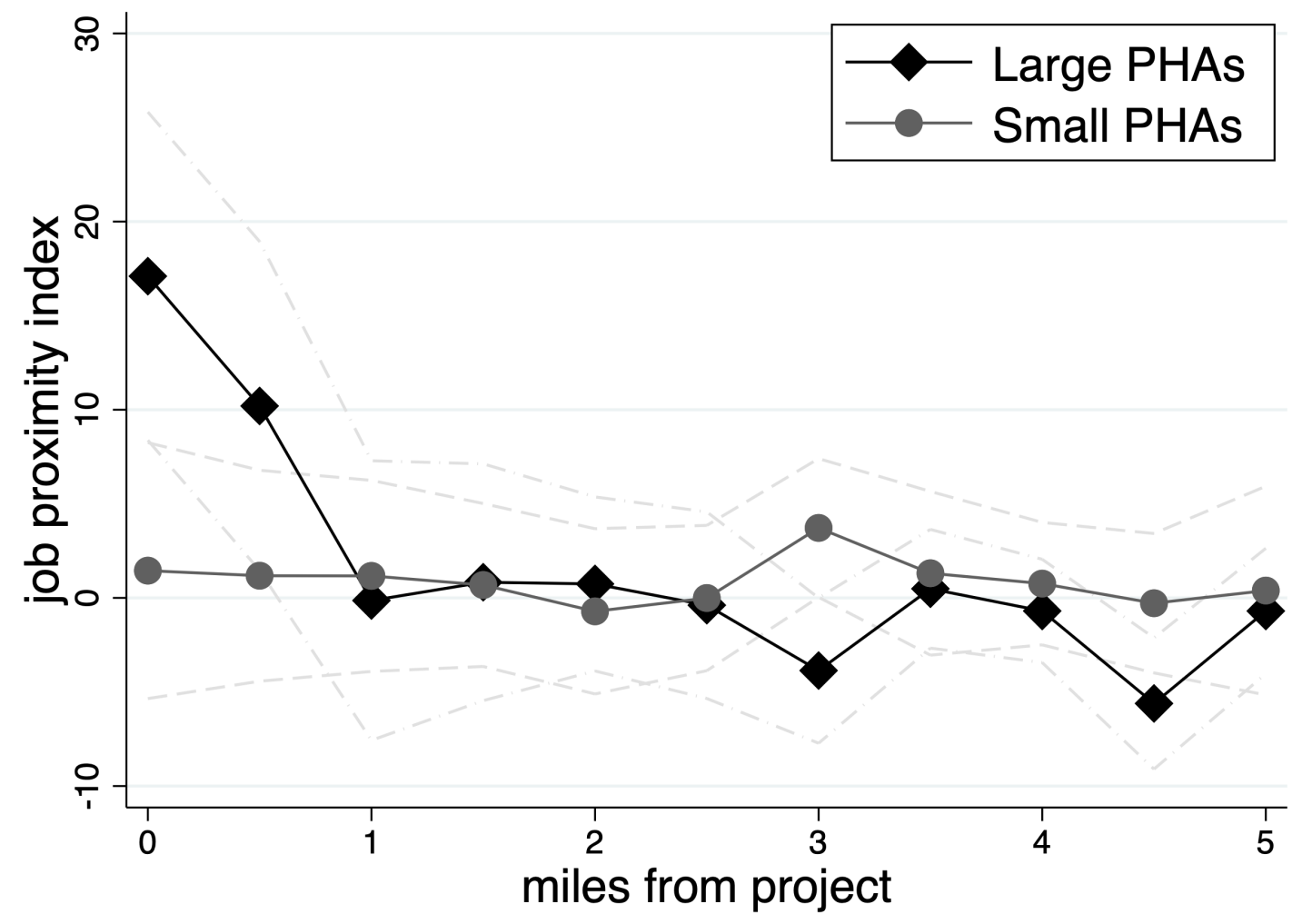

Notes: The black line with diamond markers and the grey line with circle markers plot the estimated effect of HOPE VI for large and small Public Housing Authorities (PHAs), respectively. Each point corresponds to results from a separate specification estimated via the stratification with regression methodology. The outcome for the points at the value of zero on the horizontal axis is the job proximity index (measured in 2010) for the census tract in which the project is located. The outcome for the remaining points correspond to the average job proximity index for other census tracts that are within the number of miles denoted on the horizontal axis (exclusive) and half a mile less than this value (inclusive). All stratum-level regressions are estimated on the child-year dataset and control for the base year in which the child appears in public housing, the year in which the child turns 26, and the standard vector of individual- and project- level covariates. Standard errors are clustered at the project level and are $95 \%$ confidence interval is depicted by the dashed light grey lines.

Source: Authors' calculations from matched Longitudinal Employer-Household Dynamics, Department of Housing and Urban Development, and Decennial Census files. 


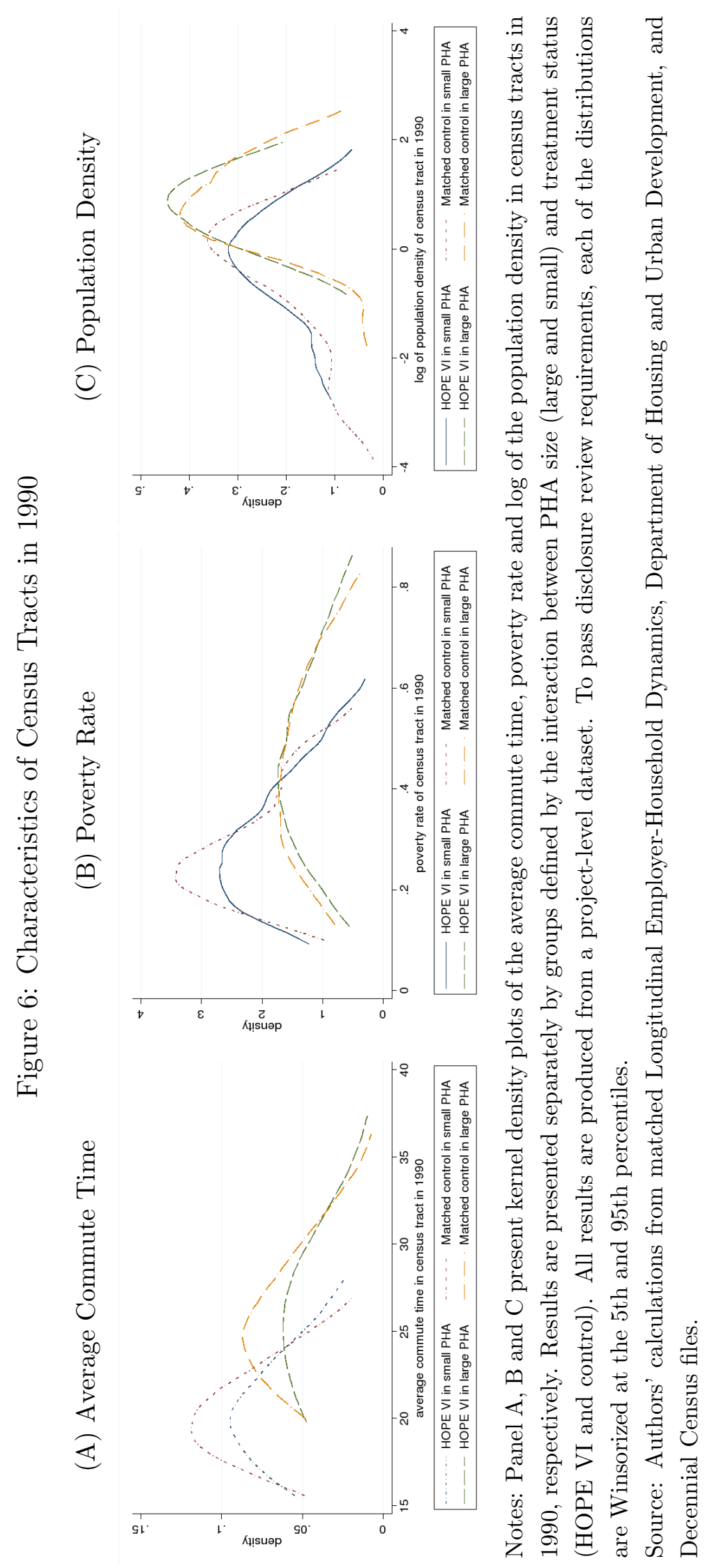




\section{Tables}

Table 1: Summary Statistics of Baseline Characteristics

\begin{tabular}{|c|c|c|c|c|c|c|c|}
\hline & \multirow{2}{*}{$\frac{\mathrm{HOPE} \text { VI }}{\text { mean }}$} & \multicolumn{3}{|c|}{ All Non-HOPE VI } & \multicolumn{3}{|c|}{ Control } \\
\hline & & mean & t-stat & $\Delta$ & mean & t-stat & $\Delta$ \\
\hline $\begin{array}{l}\text { Panel A. Neighborhood } \\
\text { median household income/1,000 }\end{array}$ & $\begin{array}{c}22.0 \\
{[11.1]}\end{array}$ & $\begin{array}{c}27.9 \\
{[11.5]}\end{array}$ & -6.68 & -0.520 & $\begin{array}{c}22.9 \\
{[10.3]}\end{array}$ & -0.936 & -0.085 \\
\hline poverty rate & $\begin{array}{l}0.374 \\
{[.206]}\end{array}$ & $\begin{array}{c}0.247 \\
{[.14]}\end{array}$ & 7.84 & 0.724 & $\begin{array}{l}0.346 \\
{[.181]}\end{array}$ & 1.60 & 0.146 \\
\hline $\log$ (population density) & $\begin{array}{l}0.033 \\
{[1.42]}\end{array}$ & $\begin{array}{l}-1.24 \\
{[2.13]}\end{array}$ & 11.2 & 0.703 & $\begin{array}{c}-0.153 \\
{[1.63]}\end{array}$ & 1.43 & 0.122 \\
\hline $\begin{array}{l}\text { Panel B. Household Head } \\
\text { household income } / 1,000\end{array}$ & $\begin{array}{c}9.00 \\
{[6.63]}\end{array}$ & $\begin{array}{c}11.3 \\
{[8.63]}\end{array}$ & -6.93 & -0.515 & $\begin{array}{c}9.65 \\
{[7.31]}\end{array}$ & -1.77 & -0.174 \\
\hline age & $\begin{array}{c}38.6 \\
{[10.1]}\end{array}$ & $\begin{array}{c}39.3 \\
{[10.1]}\end{array}$ & -2.36 & -0.167 & $\begin{array}{l}38.6 \\
{[10]}\end{array}$ & -0.096 & -0.054 \\
\hline female & $\begin{array}{l}0.904 \\
{[.294]}\end{array}$ & $\begin{array}{l}0.869 \\
{[.338]}\end{array}$ & 2.46 & 0.409 & $\begin{array}{l}0.899 \\
{[.301]}\end{array}$ & 0.338 & 0.044 \\
\hline married & $\begin{array}{l}0.078 \\
{[.268]}\end{array}$ & $\begin{array}{c}0.133 \\
{[.34]}\end{array}$ & -4.52 & -0.436 & $\begin{array}{l}0.081 \\
{[.273]}\end{array}$ & -0.241 & -0.014 \\
\hline has disability & $\begin{array}{l}0.113 \\
{[.316]}\end{array}$ & $\begin{array}{l}0.121 \\
{[.326]}\end{array}$ & -1.64 & -0.063 & $\begin{array}{l}0.111 \\
{[.314]}\end{array}$ & 0.284 & -0.003 \\
\hline number of dependents & $\begin{array}{c}2.76 \\
{[1.56]}\end{array}$ & $\begin{array}{l}2.54 \\
{[1.4]}\end{array}$ & 4.24 & 0.454 & $\begin{array}{c}2.63 \\
{[1.46]}\end{array}$ & 2.27 & 0.273 \\
\hline white non-Hispanic & $\begin{array}{l}0.064 \\
{[.244]}\end{array}$ & $\begin{array}{l}0.207 \\
{[.405]}\end{array}$ & -12.0 & -0.709 & $\begin{array}{c}0.079 \\
{[.27]}\end{array}$ & -1.16 & -0.034 \\
\hline black non-Hispanic & $\begin{array}{l}0.684 \\
{[.465]}\end{array}$ & $\begin{array}{c}0.522 \\
{[.5]}\end{array}$ & 3.67 & 0.660 & $\begin{array}{l}0.692 \\
{[.462]}\end{array}$ & -0.151 & 0.041 \\
\hline Hispanic & $\begin{array}{l}0.161 \\
{[.368]}\end{array}$ & $\begin{array}{l}0.184 \\
{[.387]}\end{array}$ & -0.575 & -0.083 & $\begin{array}{l}0.152 \\
{[.359]}\end{array}$ & 0.206 & -0.056 \\
\hline $\begin{array}{l}\text { Panel C. Children } \\
\text { age }\end{array}$ & $\begin{array}{c}13.6 \\
{[2.58]}\end{array}$ & $\begin{array}{c}13.6 \\
{[2.57]}\end{array}$ & -2.33 & -0.288 & $\begin{array}{c}13.5 \\
{[2.58]}\end{array}$ & 0.300 & -0.232 \\
\hline female & $\begin{array}{c}0.509 \\
{[.5]}\end{array}$ & $\begin{array}{c}0.507 \\
{[.5]}\end{array}$ & 0.431 & -0.137 & $\begin{array}{c}0.512 \\
{[.5]}\end{array}$ & -0.631 & -0.124 \\
\hline has disability & $\begin{array}{c}0.020 \\
{[.14]}\end{array}$ & $\begin{array}{l}0.027 \\
{[.161]}\end{array}$ & -2.79 & -0.077 & $\begin{array}{c}0.020 \\
{[.14]}\end{array}$ & -0.011 & -0.020 \\
\hline
\end{tabular}

Notes: This table presents summary statistics for the baseline variables listed in the rows. The variables in Panel A, B and $\mathrm{C}$ are characteristics of: (A) the census tract in which the projects were located measured in 1990, (B) the households or head of households and (C) the children. Column 1 presents the mean for the HOPE VI sample. Columns 2-4 (5-7) present statistics calculated from a sample that include all non-HOPE VI (control) projects. Columns 2 and 5 present the mean of the non-HOPE VI projects. Columns 3 and 6 present the t-statistic from a regression of the baseline variable in the row on an indicator for HOPE VI. Standard errors are clustered at the project level. Columns 4 and 7 present the normalized difference of the row variable between the HOPE VI and non-HOPE VI observation. Normalized differences are calcualted from data collapsed to the project level and are defined as $\Delta=\left(\bar{x}_{1}-\bar{x}_{0}\right) /\left(\sqrt{\left(s_{1}^{2}+s_{0}^{2}\right) / 2}\right)$, where $\bar{x}_{d}$ and $s_{d}$ is the sample average and variance for HOPE VI $(\mathrm{d}=1)$ and non-HOPE VI $(\mathrm{d}=0)$ observations, respectively. The standard deviation for each sample is presented in brackets below the mean.

Source: Authors' calculations from matched Longitudinal Employer-Household Dynamics, Department of Housing and Urban Development, and Decennial Census files. 
Table 2: Earnings Outcomes

qrtrs worked worked 4 qrtrs earnings / 1,000 IHS earnings

(1)

(2)

$(3)$

(4)

\begin{tabular}{lcccc}
\hline Panel A. All PHAs & & & & \\
HOPE VI & $0.057^{* * *}$ & $0.016^{* * *}$ & $0.622^{* *}$ & $0.142^{* *}$ \\
& $(0.021)$ & $(0.006)$ & $(0.282)$ & $(0.056)$ \\
control mean & 2.16 & & & \\
& {$[1.73]$} & {$[0.404$} & 8.33 & 6.3 \\
observations & 258,000 & 258,000 & 258,000 & 258,000 \\
& & & & \\
Panel B. Large PHAs & $0.076^{* * *}$ & $0.019^{* * *}$ & $0.529 *$ & $0.195^{* * *}$ \\
HOPE VI & $(0.027)$ & $(0.007)$ & $(0.287)$ & $(0.073)$ \\
& & & & 6.24 \\
& 2.14 & 0.4 & 8.44 & {$[4.55]$} \\
control mean & {$[1.73]$} & {$[0.481]$} & {$[40.5]$} & 149,000 \\
& 149,000 & 149,000 & 149,000 & \\
observations & & & & 0.045 \\
Panel C. Small PHAs & 0.022 & 0.009 & 0.794 & $(0.087)$ \\
HOPE VI & $(0.035)$ & $(0.009)$ & $(0.601)$ & 6.4 \\
& & & & {$[4.48]$} \\
& 2.2 & 0.41 & 8.12 & 109,000 \\
\hline
\end{tabular}

Notes: Panels A, B, and C present estimates from the stratification with regression estimator for all, large, and small Public Housing Authorities (PHAs), respectively. All outcome variables are annual labor market outcomes measured in the year in which the child turns 26. In columns 1-4 the outcome variables are: the number of quarters worked, an indicator equal to one if the child had positive earnings for all four quarters, earnings $/ 1,000$ winsorized at the $99^{\text {th }}$ percentile, and the inverse hyperbolic sine (IHS) of earnings. All stratum-level regressions control for the base year in which the child appears in public housing, the year in which the child turns 26 , and the standard vector of individual- and projectlevel covariates. Standard errors are clustered at the project level and are presented in parentheses. The mean and standard deviation, presented in brackets, of the outcome for the control group are a weighted aggregate of stratum-level statistics, where the weights are proportional to the number of treated individuals in a strata.

Source: Authors' calculations from matched Longitudinal Employer-Household Dynamics, Department of Housing and Urban Development, and Decennial Census files.

$* * * \mathrm{p} \leq 0.01,{ }^{* *} \mathrm{p} \leq 0.05,{ }^{*} \mathrm{p} \leq 0.10$. 
Table 3: Heterogeneous Effects by Demographics, for Large PHAs

IHS of Earnings at Age 26

\begin{tabular}{|c|c|c|c|c|}
\hline & (1) & $(2)$ & (3) & (4) \\
\hline HOPE VI & $\begin{array}{c}0.189 \\
(0.119)\end{array}$ & $\begin{array}{c}0.071 \\
(0.085)\end{array}$ & $\begin{array}{l}-0.194 \\
(0.236)\end{array}$ & $\begin{array}{c}0.059 \\
(0.085)\end{array}$ \\
\hline HOPE VI $\times(18$-age at demolition) & $\begin{array}{c}0.002 \\
(0.020)\end{array}$ & & & \\
\hline HOPE VI $\times$ male & & $\begin{array}{c}0.254^{* *} \\
(0.122)\end{array}$ & & \\
\hline HOPE VI $\times$ black & & & $\begin{array}{l}0.425^{*} \\
(0.252)\end{array}$ & \\
\hline HOPE VI $\times$ Hispanic & & & $\begin{array}{c}0.422 \\
(0.326)\end{array}$ & \\
\hline HOPE VI×other & & & $\begin{array}{c}0.354 \\
(0.295)\end{array}$ & \\
\hline HOPE VI $\times$ male $\times$ non-white & & & & $\begin{array}{c}0.287^{* *} \\
(0.126)\end{array}$ \\
\hline observations & 149,000 & 149,000 & 149,000 & 149,000 \\
\hline
\end{tabular}

Notes: The table presents estimates from the stratification with regression estimator for large Public Housing Authorities (PHAs) only. The outcome variable is the inverse hyperbolic sine (IHS) of annual earnings measured in the year the child turns 26. Each column presents results from a seperate regression in which the inidcator for HOPE VI is interacted with a different individual-level variable. Note that there are four mutually exclusive race/ethnicity categories, including: white (non-Hispanic), black (nonHispanic), Hispanic, and other non-Hispanic. All stratum-level regressions control for the base year in which the child appears in public housing, the year in which the child turns 26 and the standard vector of individual- and project-level covariates. Standard errors are clustered at the project-level and are presented in parentheses.

Source: Authors' calculations from matched Longitudinal Employer-Household Dynamics, Department of Housing and Urban Development, and Decennial Census files.

*** $\mathrm{p} \leq 0.01,{ }^{* *} \mathrm{p} \leq 0.05,{ }^{*} \mathrm{p} \leq 0.10$. 
Table 4: Household Head Housing Outcomes

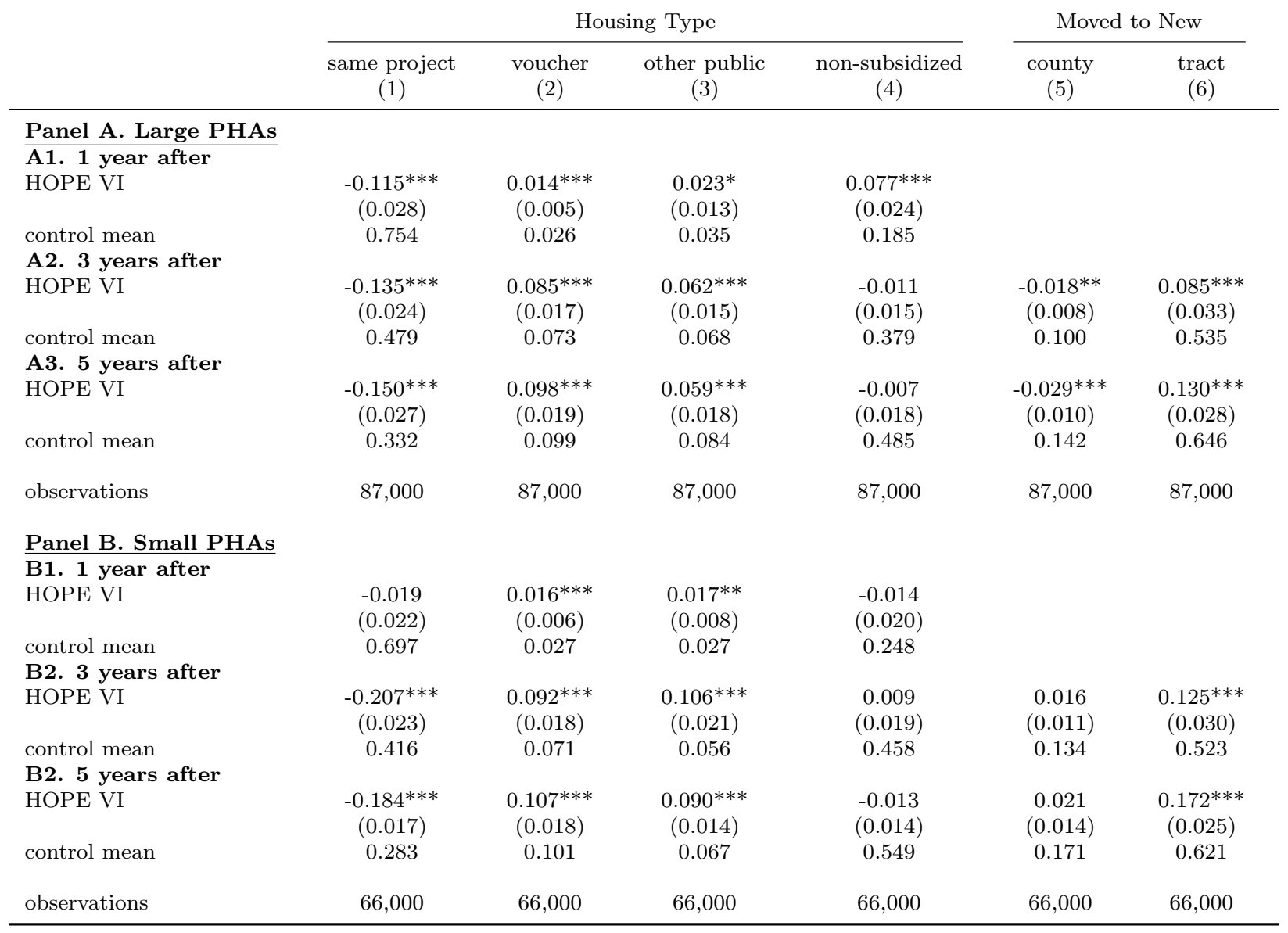

Notes: Panels A and B present estimates from the stratification with regression estimator for large and small Public Housing Authorities (PHAs), respectively. Outcomes are measured: one year after the refernce year in panels $\mathrm{A} 1$ and B1, three years after the reference year in panels A2 and B2, and five years after the reference year in panels A3 and B3. The outcomes in columns 1-4 are indicator variables with a value equal to one if the head of household appears in the same project, other public housing, voucher housing, or other housing after the reference year (categories are mutually exclusive). In columns 5-7 the outcomes are indicators equal to one if the head of household moved to a new state, county, and census tract, respectively. Each stratum-level regression contains a fixed effect for the base year in which the household appears in public housing as well as the standard set of project- and individuallevel covariates. Standard errors are clustered at the project-level and are presented in parentheses. The mean and standard deviation, presented in brackets, of the outcome for the control group are a weighted aggregate of strata-level statistics, where the weights are proportional to the number of treated individuals in a strata.

Source: Authors' calculations from matched Longitudinal Employer-Household Dynamics, Department of Housing and Urban Development, and Decennial Census files.

*** $\mathrm{p} \leq 0.01,{ }^{* *} \mathrm{p} \leq 0.05,{ }^{*} \mathrm{p} \leq 0.10$. 
Table 5: Household Head Neighborhood Outcomes

$\begin{array}{ccc}\begin{array}{c}\text { school proficiency } \\ \text { index }\end{array} & \text { poverty rate } & \begin{array}{c}\text { share white } \\ \text { non-Hispanic }\end{array} \\ (1) & (2) & (3)\end{array}$

\begin{tabular}{lccc}
\hline Panel A. Large PHAs & & & \\
HOPE VI & 0.084 & -0.017 & 0.022 \\
& $(1.660)$ & $(0.012)$ & $(0.017)$ \\
& & & 0.192 \\
control mean & 23.900 & 0.416 & {$[0.235]$} \\
& {$[16.900]$} & {$[0.181]$} & 87,000 \\
observations & 87,000 & 87,000 & \\
Panel B. Small PHAs & & & 0.020 \\
HOPE VI & -0.497 & -0.012 & $(0.022)$ \\
& $(2.130)$ & $(0.011)$ & 0.367 \\
control mean & 30.500 & & {$[0.303]$} \\
& {$[20.200]$} & 0.289 & 66,000 \\
\hline
\end{tabular}

Notes: Panels A and B present estimates from the stratification with regression estimator for large and small Public Housing Authorities (PHAs), respectively. All outcomes are an average characteristic of the census tracts in which the head of household resided in 1-5 years after the reference year. The characteristic in column 1 is the school proficiency index, which measures of the quality of the public schools in that area. In columns 2 and 3 the characteristics are the share of residents who are below the poverty line and white non-Hispanic, respectively. Each stratum-level regression contains a fixed effect for the base year in which the household appears in public housing as well as the standard set of project- and individual-level covariates. Standard errors are clustered at the project-level and are presented in parentheses. The mean and standard deviation, presented in brackets, of the outcome for the control group are a weighted aggregate of strata-level statistics, where the weights are proportional to the number of treated individuals in a strata.

Source: Authors' calculations from matched Longitudinal Employer-Household Dynamics, Department of Housing and Urban Development, and Decennial Census files.

$* * * \mathrm{p} \leq 0.01,{ }^{* *} \mathrm{p} \leq 0.05, * \mathrm{p} \leq 0.10$. 
Table 6: Household Head Earnings Outcomes

$\frac{5 \text { Years After }}{\text { qrtrs worked } \quad \text { IHS earnings }}$

(1)

\section{Panel A. Large PHAs HOPE VI}

control mean

observations

5.650

[1.810]

[4.800]

\begin{tabular}{|c|c|}
\hline $10 \mathrm{Ye}$ & After \\
\hline $\begin{array}{c}\text { qrtrs worked } \\
(3)\end{array}$ & $\begin{array}{c}\text { IHS earnings } \\
(4)\end{array}$ \\
\hline
\end{tabular}

10 Years After

$-0.134$

1.700

[1.840]

4.840

87,000

87,000

\begin{tabular}{lcccc} 
Panel B. Small PHAs & & & & \\
HOPE VI & -0.005 & 0.011 & 0.001 & 0.004 \\
& $(0.039)$ & $(0.099)$ & $(0.041)$ & $(0.109)$ \\
& & & & \\
control mean & 2.070 & 5.880 & 1.790 & 5.050 \\
& {$[1.810]$} & {$[4.750]$} & {$[1.860]$} & {$[4.940]$} \\
observations & 66,000 & 66,000 & 66,000 & 66,000 \\
\hline
\end{tabular}

Notes: Panels A and B present estimates from the stratification with regression estimator for large and small Public Housing Authorities (PHAs), respectively. All outcomes are annual labor market outcomes of the head of household measured 5 and 10 years after the reference year for columns 1-2 and 3-4, respectively. In odd and even numbered columns the outcome variables are the number of quarters worked and the inverse hyperbolic since of annual earnings, respectively. Each stratum-level regression contains a fixed effect for the base year in which the household appears in public housing as well as the standard vector of project- and individual-level covariates. Standard errors are clustered at the projectlevel and are presented in parentheses. The mean and standard deviation, presented in brackets, of the outcome for the control group are a weighted aggregate of strata-level statistics, where the weights are proportional to the number of treated individuals in a strata.

Source: Authors' calculations from matched Longitudinal Employer-Household Dynamics, Department of Housing and Urban Development, and Decennial Census files.

*** $\mathrm{p} \leq 0.01,{ }^{* *} \mathrm{p} \leq 0.05,{ }^{*} \mathrm{p} \leq 0.10$. 


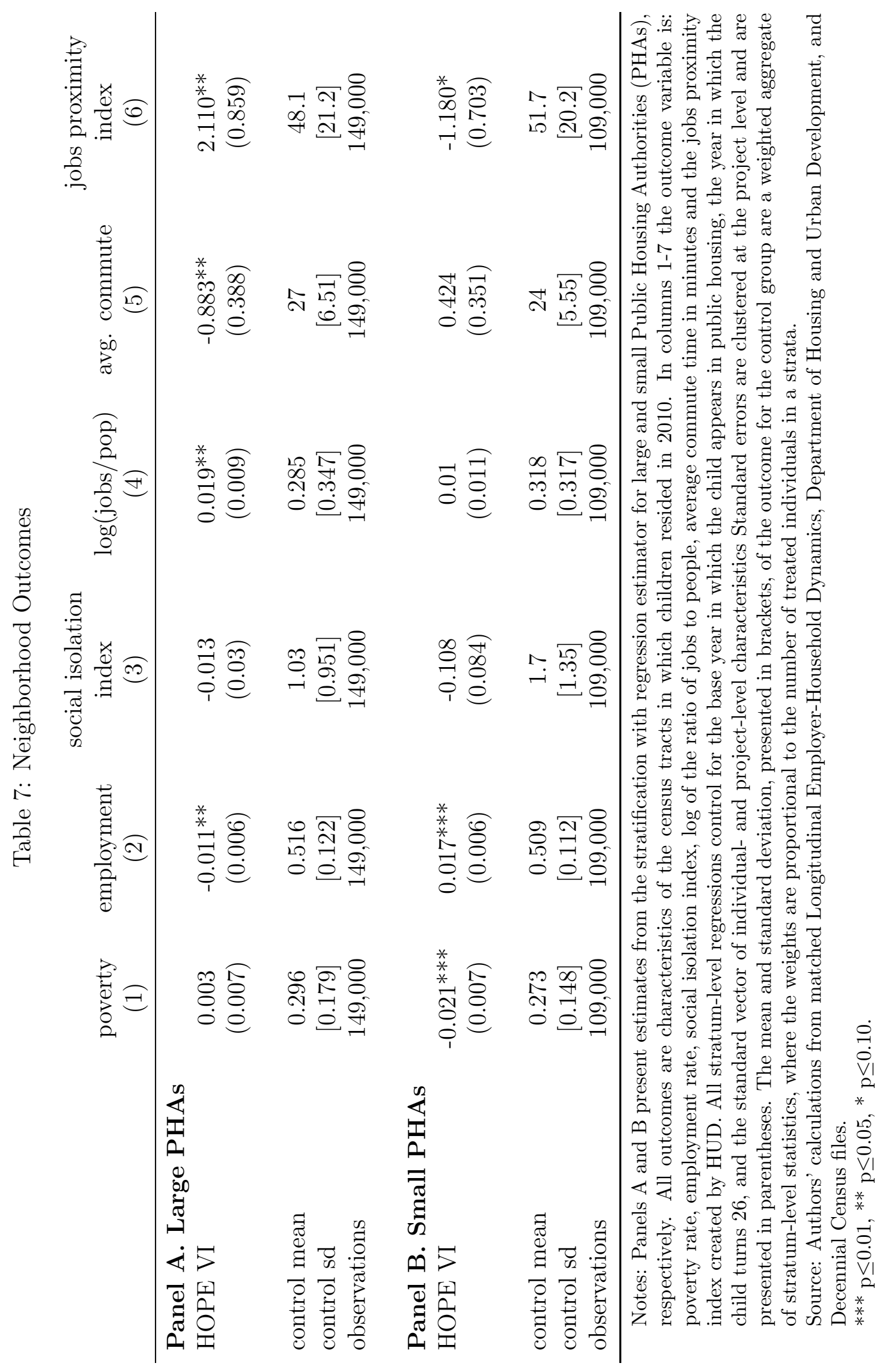


Table 8: Heterogeneous Effects by Neighborhood, for Large PHAs

IHS of Earnings at Age 26

$(1)$

\begin{tabular}{lc}
\hline HOPE VI & $0.180^{* *}$ \\
& $(0.072)$ \\
log population density & $-0.110^{* *}$ \\
& $(0.052)$ \\
HOPE VI $\times$ log population density & $0.192^{* *}$ \\
& $(0.082)$
\end{tabular}

average commute time

HOPE VI $\times$ average commute time

poverty rate

HOPE VI $\times$ poverty rate

observations $\quad 149,000 \quad 149,000 \quad 149,000$

Notes: The table presents estimates from the stratification with regression estimator for large Public Housing Authorities (PHAs) only. The outcome variable in all specifications is the inverse hyperbolic sine (IHS) of annual earnings measured at age 26. Columns 1-3 presents esitmates from models in which the indicator for HOPE VI is interacted with a characteristic of the census tract in which the project is located measured in 1990. For columns 1-3 these characteristics include the $\log$ of the popoulation density, the average commute time in minutes and the poverty rate, all three of which are normalized by substracting by the mean of the control group and dividing by the standard deviation of the control group. All stratum-level regressions control for the base year in which the child appears in public housing, the year in which the child turns 26, and the standard vector of individual- and project-level covariates. Standard errors are clustered at the project-level and are presented in parentheses. The mean and standard deviation, presented in brackets, of the outcome for the control group are a weighted aggregate of stratum-level statistics, where the weights are proportional to the number of treated individuals in a strata.

Source: Authors' calculations from matched Longitudinal Employer-Household Dynamics, Department of Housing and Urban Development, and Decennial Census files.

$* * * \mathrm{p} \leq 0.01, * * \mathrm{p} \leq 0.05, * \mathrm{p} \leq 0.10$. 